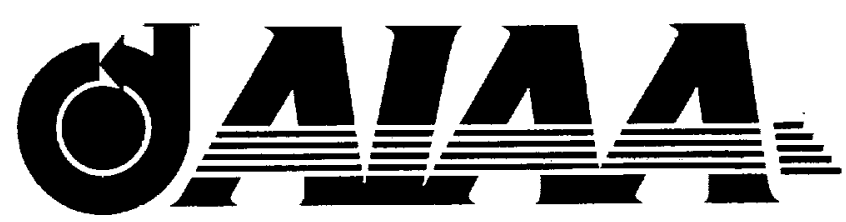

AIAA-2001-0912

Reynolds Number Effects on a Supersonic Transport at Transonic Conditions (Invited)

R. A. Wahls, L. R. Owens, and S. M. B. Rivers

NASA Langley Research Center

Hampton, Virginia

39th AIAA Aerospace Sciences Meeting \& Exhibit 8-11 January 2001

Reno, Nevada

For permission to copy or republish, contact the American Institute of Aeronautics and Astronautics 1801 Alexander Bell Drive, Suite 500, Reston, VA 20191-4344 



\title{
REYNOLDS NUMBER EFFECTS ON A SUPERSONIC TRANSPORT AT TRANSONIC CONDITIONS
}

\author{
R. A. Wahls', L. R. Owens ${ }^{\dagger}$, and S. M. B. Rivers ${ }^{\dagger}$ \\ Aerodynamics, Aerothermodynamics, and Acoustics Competency \\ NASA Langley Research Center \\ Hampton, Virginia
}

\begin{abstract}
A High Speed Civil Transport configuration was tested in the National Transonic Facility at the NASA Langley Research Center as part of NASA's High Speed Research Program. The primary purposes of the tests were to assess Reynolds number scale effects and the high Reynolds number aerodynamic characteristics of a realistic, second generation supersonic transport while providing data for the assessment of computational methods. The tests included longitudinal and lateral/directional studies at lowspeed high-lift and transonic conditions across a range of Reynolds numbers from that available in conventional wind tunnels to near flight conditions. Results are presented which focus on both the Reynolds number and static aeroelastic sensitivities of longitudinal characteristics at Mach 0.90 for a configuration without an empennage.
\end{abstract}

\section{INTRODUCTION}

Ground to flight scaling remains one of many challenges facing today's designers of aerospace vehicles. The goal of ground to flight scaling is the preflight prediction of multiple key aerodynamic characteristics with sufficient accuracy to meet both performance guarantees and certification requirements. In other words, the designer and his company strive to know the performance of their vehicle with high confidence prior to flight, thus enabling optimal design trades prior to flight and the elimination of costly fixes to the aircraft after the first flight. Specific challenges,

Assistant Head, Configuration Aerodynamics Branch, Associate Fellow, AIAA

${ }^{\dagger}$ Aerospace Engineer, Subsonic Aerodynamics Branch, Senior Member, AIAA

${ }^{\ddagger}$ Aerospace Engineer, Configuration Aerodynamics Branch, Member, AIAA

Copyright (C) 2001 by the American Institute of Aeronautics and Astronautics, Inc. No copyright is asserted in the United States under Title $17, \mathrm{U}$. S. Code. The U. S. Government has a royaltyfree license to exercise all rights under the copyright claimed herein for Governmental Purposes. All other rights are reserved by the copyright owner. experiences, and suggested approaches to ground to flight scaling have been documented extensively over the years for a variety of vehicle classes (refs. 1, 2, among many others). Reynolds number effects are foremost among many factors affecting successful ground to flight scaling (refs. 3 -5). The Reynolds number is the ratio of inertial to viscous forces, and is the primary aerodynamic scaling parameter used to relate sub-scale wind tunnel models to full-scale aircraft in flight. The challenge of Reynolds number scaling increases with the size of a full-scale aircraft as the Reynolds number increment between that obtainable in conventional wind tunnels and flight conditions expands. Additionally, the challenge for both wind tunnel and computational approaches increases as flow features become dominated by viscoussensitive phenomena such as boundary-layer transition, shock/boundary layer interaction, and separation onset and progression.

The present investigation was conducted in support of NASA's High Speed Research (HSR) Program, Phase II, which was conducted from 1993-1999 (ref. 6). The objective of this program, which was NASA sponsored and jointly executed with US industry, was to develop critical high-risk aiframe and propulsion technologies to enable industry development of an economically viable and environmentally acceptable second generation high speed civil transport (HSCT). Aerodynamic performance, one of several broad airfame technology areas, included tasks to address Configuration Aerodynamics for highspeed conditions and High-Lift Technology for take-off and landing. These elements encompassed not only the challenge of efficient supersonic cruise flight, but also the off-design challenges (ref. 7) of efficient transonic cruise and acceleration, and quiet high-performance take-off and landing. The objective of the Configuration Aerodynamics task was the development of aerodynamic drag reduction, stability and control, and propulsion aiframe integration technologies required to support the HSCT development 
process. Towards this goal, computational and empirical based aerodynamic design tools were developed, evaluated, and validated through ground based experimental testing. The development and assessment of methods for ground to flight scaling were included as part of this effort. Figure 1 shows the nominal mission profile for the baseline reference configuration used in the HSR program, and comparison to the capability of several wind tunnels. The baseline reference configuration, known as the Reference $\mathrm{H}$, was provided by Boeing and represented a Mach 2.4, 300 passenger aircraft with a 5000 nautical mile range.

A series of wind tunnel tests was executed in the National Transonic Facility (NTF) at NASA Langley Research Center (LaRC) across a wide range of Reynolds numbers from that available in conventional wind tunnels to near flight condition at subsonic and transonic Mach numbers. The tests included longitudinal and lateral/directional studies with and without an empennage at lowspeed high-lift and transonic conditions. This paper presents results focused on the Reynolds number sensitivities of longitudinal characteristics at transonic conditions for the configuration without the empennage; reference 8 provides similar results for subsonic, high-lift conditions.

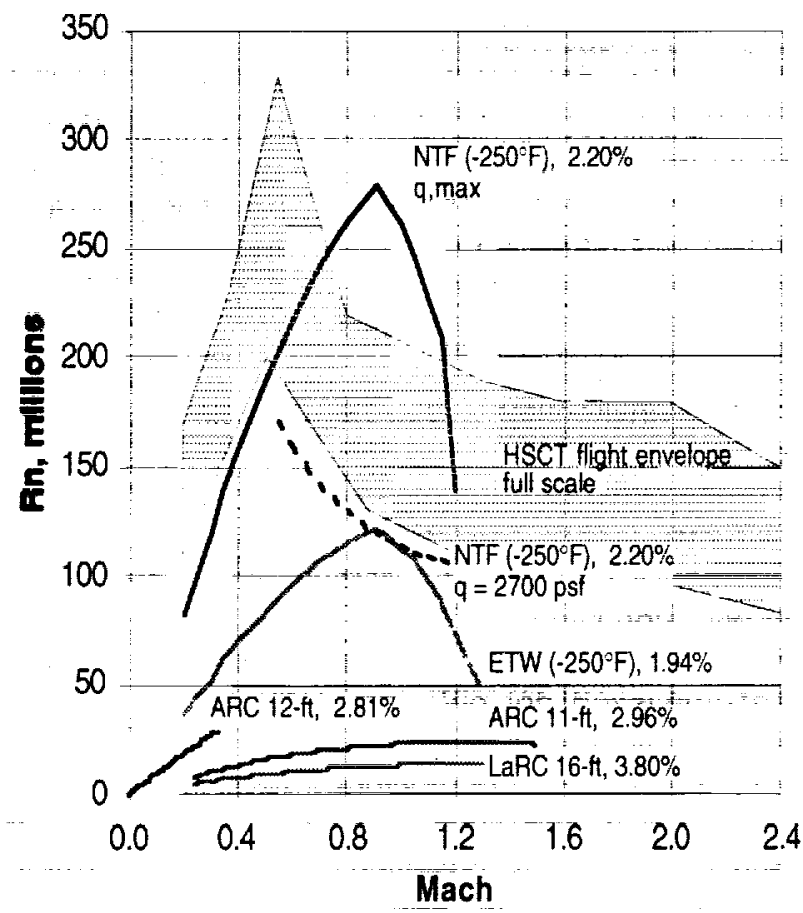

Figure 1. Nominal HSCT mission profile and wind tunnel capabilities (model scale adjusted to test section size, $2.2 \%$ scale in the NTF is the baseline size).
TERMS, ABBREVIATIONS, \& ACRONYMS

ARC NASA Ames Reseach Center

BL butt-line, model coordinates

$\mathrm{Cl}_{95} \quad 95 \%$ confidence interval

c local chord length

$C_{D} \quad$ drag coefficient

$C_{L} \quad$ lift coefficient

$\mathrm{C}_{\mathrm{M}}$ pitching-moment coefficient referenced to $0.50 \mathrm{mac}$

$C_{p} \quad$ pressure coefficient

ETW European Transonic Windtunnel

FS fuselage station, model coordinates

HSCT High Speed Civil Transport

HSR High Speed Research

LaRC Langley Research Center

$M \quad$ Mach number

mac mean aerodynamic chord

NTF National Transonic Facility

$P_{T} \quad$ total pressure

$q \quad$ dynamic pressure

Rn Reynolds number based on mac

r local leading-edge radius

$T_{T} \quad$ total temperature

$t_{\max }$. local maximum airfoil thickness

WL waterline, model coordinates

$\alpha \quad$ angle of attack

$\eta \quad$ nondimensional semispan station

$\theta \quad$ sectional wing twist change, relative to wind-off twist

\section{EXPERIMENTAL APPROACH Facility Description}

The NTF (ref. 9) is a unique national facility (fig. 2) that enables tests of aircraft configurations at conditions ranging from subsonic to low supersonic speeds at Reynolds numbers up to full-scale flight values, depending on the aircraft type and size. The facility (fig. 3 ) is a fan-driven, closed-circuit, continuous-flow, pressurized wind tunnel capable of operating in either dry air at warm temperatures or nitrogen from warm to cryogenic temperatures. The test section is $8.2 \mathrm{ft}$ by $8.2 \mathrm{ft}$ in cross section and $25 \mathrm{ft}$ in length. The test section floor and ceiling are slotted (6 percent open), and the sidewalls are solid. Freestream turbulence is damped by four screens and a 14.95:1 contraction ratio from the settling chamber to the test section. Fan-noise effects are minimized by an acoustic treatment both upstream and downstream of the fan. A detailed assessment of the dynamic flow quality in the NTF is reported in reference 10 , and reconfirmed with more recent measurements shown in reference 11 . The NTF is capable of an 
absolute pressure range from 15 psi to $125 \mathrm{psi}$, a temperature range from $-320^{\circ} \mathrm{F}$ to $150^{\circ} \mathrm{F}$, a Mach number range from 0.2 to 1.2 , and a maximum Reynolds number of $146 \times 10^{6}$ per $\mathrm{ft}$ at Mach 1 . Further facility details can be found in reference 12.

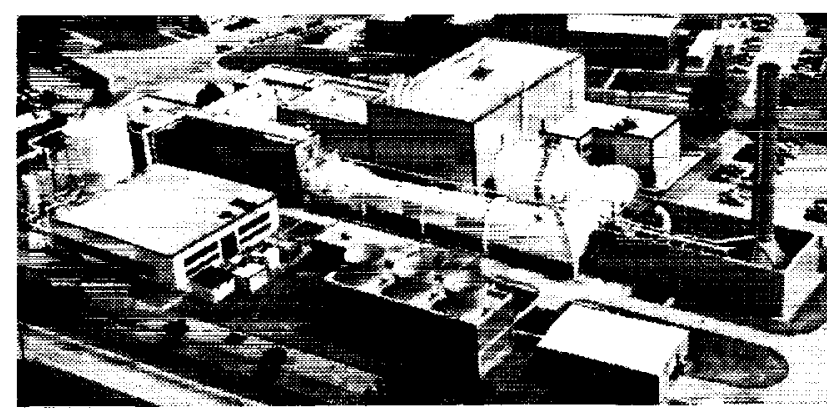

Figure 2. External view of the NTF.

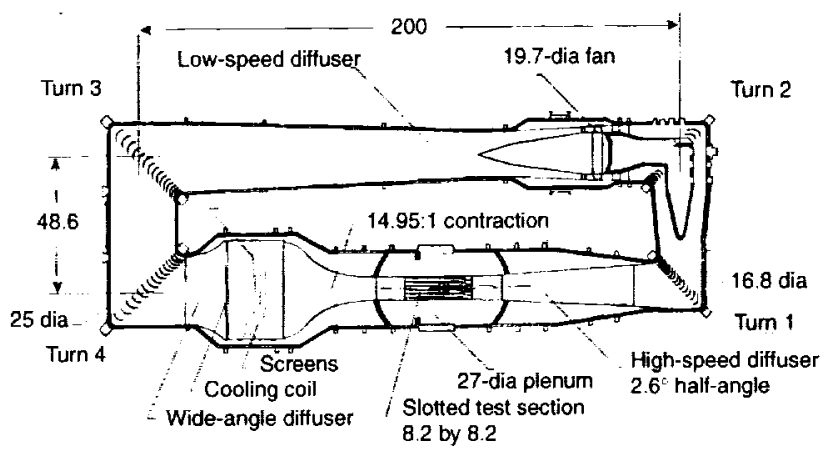

Figure 3. NTF clrcuit diagram (linear dimensions in ft).

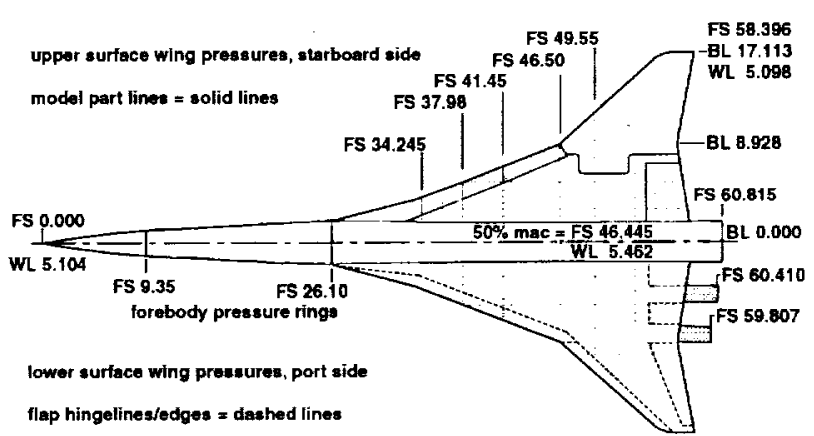

Figure 4. Model drawing with pressure locations (linear dimensions in inches).

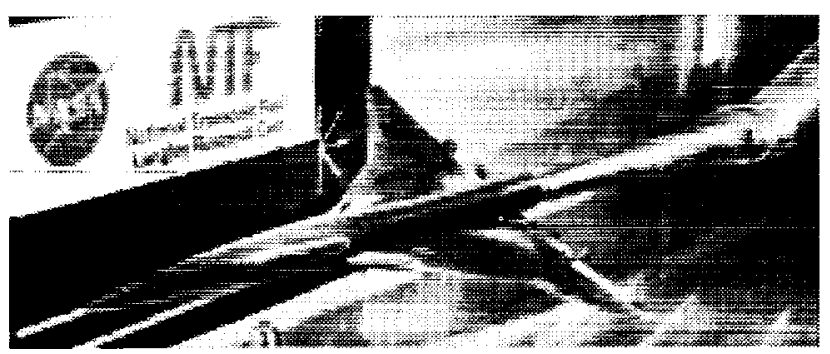

Figure 5. $2.2 \%$ Reference $H$ model in the NTF.

\section{Model Description}

The wind-tunnel model is a $2.2 \%$ scale representation of the HSR baseline configuration known as Reference $\mathrm{H}$. Although the full model with empennage was tested during the HSR program, the present paper focuses on results obtained for the wing/body configuration with the body truncated slightly aft of the wing trailing edge. Figure 4 shows a planform drawing of the model with wing pressure taps and reference locations noted. The model has a cranked-delta wing planform with an aspect ratio of 2.367, a span of 34.23 inches, and a mean aerodynamic chord of 22.71 inches. The inboard wing $(\eta \leq 0.522)$ has a blunt ( $r / c \sim 0.0025$ to 0.0030 ), subsonic leading edge with a sweep change from 76 to $68.5 \mathrm{deg}$ at $\eta=0.226$, a twist varying from approximately $1 \mathrm{deg}$ near $\eta=0.10$ to -2 deg near $\eta=0.50$, and variable thickness ratio $\left(\mathrm{t}_{\mathrm{max}} / \mathrm{c}\right)$ from 0.043 to 0.024 . The outboard, supersonic leading edge is sharp, swept $48 \mathrm{deg}$, has a constant twist of $-1.6 \mathrm{deg}$ for $\eta \geq$ 0.65 , and a constant thickness ratio of 0.024 . The reference area for the model is $3.436 \mathrm{ft}^{2}$. Table 1 provides several key ratios relating the model size to the NTF test section.

\begin{tabular}{|r|c|}
\hline ref. area / NTF cross sectional area & 0.0515 \\
\hline model span / NTF width & 0.3478 \\
\hline solid blockage ratio, $\alpha=0$ deg & 0.0022 \\
\hline
\end{tabular}

Table 1. Model size relative to the NTF test section.

The model was designed and constructed specifically for testing in the cryogenic, pressurized conditions of the NTF, where dynamic pressures reached approximately 2700 psf during these tests; the model jig shape was that of the Mach 2.4 cruise design point. The model was built of maraging steel with a surface finish of $8-16 \mu$ inches (root mean square), and a contour tolerance of \pm 0.005 inches. The model is shown in figure 5 mounted in the NTF test section on a straight sting; the sting mounts to a 6-deg offset stub sting which in turn mounts to the facility arcsector resulting in a model angle-of-attack range from -4 to 24 degrees.

The model has multiple inboard leading and trailing edge parts, multiple outboard wing panels each with different leading and trailing edge deflections, and four dettachable, 8.43 inch long, constant internal diameter (1.236 inches), circular flow-through nacelles with boundary-layer diverters located between the wing and nacelle. The inboard nacelles are rigged with toe-in and 
pitch (nose down) angles of 1 and $4.17 \mathrm{deg}$, respectively; the outboard nacelles are rigged with toe-in and pitch angles of 2.4 and $2.84 \mathrm{deg}$, respectively. The multiple leading and trailing edge parts in combination with the multiple outboard panels enabled testing of a variety of configurations including the baseline (supersonic cruise), take-off, landing, stall recovery, and transonic cruise configurations as defined in table 2. Results for the baseline and transonic cruise configurations (with and without the nacelle/diverters) are included herein.

The model was instrumented with 48 forebody pressures distributed circumferentially at 2 fuselage stations and 146 wing pressures distributed in both spanwise and chordwise rows on the starboard upper and port lower surfaces of the wing, as shown in figure 4. Additionally, one inboard and one outboard nacelle were instrumented with an internal Preston tube, and 6 nacelle base pressure taps enabling correction for nacelle internal and base drag effects.

\begin{tabular}{|c|c|c|}
\hline Designation & $\begin{array}{c}\text { LE Deflection, deg } \\
\text { Inboard/Outboard }\end{array}$ & $\begin{array}{c}\text { TE Deflection, deg } \\
\text { inboard/Outboard }\end{array}$ \\
\hline \hline Baseline & $0 / 0$ & $0 / 0$ \\
\hline Take-Off & $30 / 30$ & $10 / 10$ \\
\hline Landing & $30 / 30$ & $20 / 20$ \\
\hline Stall Recovery & $50 / 50$ & $30 / 30$ \\
\hline Transonic Cruise & $0 / 10$ & $0 / 3$ \\
\hline
\end{tabular}

Table 2. Available Wing Configurations.

\begin{tabular}{|c|c|c|}
\hline Component & $\begin{array}{c}\text { Full-Scale } \\
\text { Load }\end{array}$ & $\begin{array}{c}\text { Nominal Accuracy } \\
95 \% \text { confidence }\end{array}$ \\
\hline \hline Normal, lbs & \pm 6500 & $\pm 0.09 \%$ full-scale \\
\hline Axial, lbs & \pm 400 & $\pm 0.30 \%$ full-scale \\
\hline Side, lbs & \pm 4000 & $\pm 0.18 \%$ full-scale \\
\hline Pitch, in-lbs & \pm 13000 & $\pm 0.09 \%$ full-scale \\
\hline Yaw, in-lbs & \pm 6500 & $\pm 0.18 \%$ full-scale \\
\hline Roll, in-lbs & \pm 9000 & $\pm 0.29 \%$ full-scale \\
\hline
\end{tabular}

Table 3. NTF-113 balance capacity and accuracy.

\section{Instrumentation}

Aerodynamic force and moment data were obtained with an internal, unheated, sixcomponent, strain gauge balance. The test results reported herein were acquired over multiple tests over a period of several years. Each test, however, used one of the NTF-113-class balances, each of which has the identical load capacity shown in table 3. Though specific calibration data varied slightly from test to test, the nominal quoted accuracy remained the same and is also shown in table 3 . An internal, heated accelerometer package was used to measure the onboard angle of attack; quoted accuracy of the package under smooth operating wind tunnel conditions is \pm 0.01 deg (ref. 13). Mode! pressure measurements were obtained using three 48-port, 30-psid, onboard, heated, electronically scanned pressure (ESP) transducers with a quoted accuracy of $\pm 0.2 \%$ of full-scale (worst case) throughout the range. The body cavity pressure was measured with a heated, 5-psid ESP module located in the facility arcsector. Wing deformation measurements were made at 3 spanwise stations, $\eta=0.635,0.778$, and 0.922 , using a video model deformation system (ref. 14). The system provided sectional twist change data relative to the wind-off shape with a quoted accuracy of $\pm 0.10 \mathrm{deg}$.

The primary measured flow variables include both the total and static pressures and the total temperature. Mach number, Reynolds number, and dynamic pressure are calculated from these measured parameters. A complete description of these measurements and subsequent calculations is given in reference 15.

\section{Data Reduction and Corrections}

Information on the various instrumentation devices, the data acquisition and control computers, and the data reduction algorithms for the different measurement systems is provided in reference 15. Standard balance, angle-of-attack, and tunnel parameter corrections have been applied. Note that the use of unheated balances in the cryogenic environment requires additional attention towards temperature compensation. The temperature compensation methods are designed to correct balance output due to thermal loads (refs. 15,16). Body cavity pressure and nacelle internal drag and base pressure corrections were applied based on the measurements described previously. The angle of attack was corrected for flow angularity (upflow) by measurement of both upright and inverted model force data for a given configuration and flow condition. Wall and model support interference effects have not been accounted for in the data; these effects were minimized through model sizing (table 1), particularly for conditions below Mach 0.96 . 


\section{Test Conditions}

The NTF allows testing across a wide range of Reynolds numbers from that available in conventional wind tunnels to near flight conditions at subsonic and transonic Mach numbers. Tests of the $2.2 \%$ Reference $H$ model spanned Mach numbers from 0.30 to 1.10 , and Reynolds numbers from 4 to 120 million based on the mean aerodynamic chord. The present paper focuses on the transonic cruise regime, and specifically at Mach 0.90 for a Reynolds number range from 10 to 120 million. Figure 1 indicates the relationship of the NTF test conditions to flight, and figure 6 provides the NTF operational envelope for Mach 0.90 with specific test points identified. Full-scale flight Reynolds numbers were not obtainable due to the large size of the full-scale aircraft and model size and load limitations ( $q=2700$ psf boundary in figure 1). The majority of the testing was limited to a maximum Reynolds number of 80 million with a dynamic pressure of approximately 1800 psf due to adverse model dynamics; limited data was acquired with dynamic pressures near 2700 psf for Reynolds numbers of 80 and 120 million.

The goals of assessing Reynolds number scale effects and extrapolation to flight conditions required a series of intermediate conditions to better identify trends. As seen in figure 6 , the desired Reynolds number range could not be covered at a constant total pressure level, and thus dynamic pressure level. However, the independent control of total pressure, total temperature, and fan speed in the NTF allow the isolation of pure Reynolds effects, pure static aeroelastic (dynamic pressure) effects, and pure

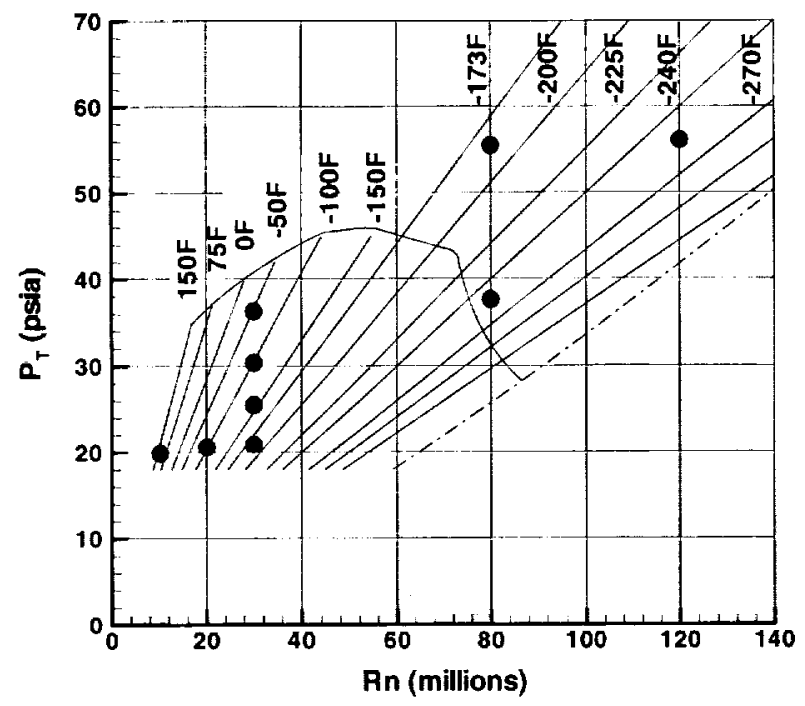

Figure 6. NTF operational envelope, Mach $=0.90$. compressibility (Mach) effects. Several conditions are used to isolate static aeroelastic effects from the Reynolds number effects for Mach 0.90 as shown in figure 6 . During Reynolds number sweeps, it is actually the ratio of dynamic pressure (q) to the model material modulus of elasticity $(E)$ that is held constant to maintain a constant static aeroelastic state $(q / E)$ due to the variability of the modulus of elasticity over the temperature range of the NTF.

\section{Boundary-Layer Transition}

A basic strategy used at the NTF includes testing at high Reynolds number conditions with free transition. The high Reynolds number test condition typically corresponds to a design flight condition. To anchor the NTF data to low Reynolds number data obtained in a conventional wind tunnel, the NTF model is usually tested at a matching low Reynolds number condition with the boundary-layer tripping (forced transition) strategy used in that facility. The majority of the data for the $2.2 \%$ Reference $\mathrm{H}$ model was not acquired with fixed transition on the wing, primarily due to the potential at the time for a one-third-scale flight test (which never occurred) anticipated to fly at conditions susceptible to transitional flow. Limited data was acquired with either a 0.125 inch wide strip of carborundum grit or a row of discrete epoxy disks sized and located based on traditional criteria (ref. 17). Transition was consistently fixed on the forebody with a ring of carborundum grit located 1.5 inches from the nose, and on the nacelle internal surface to facilitate the internal nacelle drag correction.

\section{RESULTS \& DISCUSSION}

The purpose of this paper is to document the Reynolds number sensitivities of longitudinal aerodynamic characteristics for a relevant, supersonic transport configuration at conditions representative of transonic cruise, Mach 0.90 . Though the configuration was tested with an empennage, the present results are limited to the wing/body configuration with and without installed nacelles. Figure 7 presents representative data for the baseline and transonic cruise configurations at Reynolds numbers of 10 and 80 million, and is provided to indicate the basic, longitudinal aerodynamic characteristics of the configuration. The data as acquired, and presented in figure 7 , include the combined effects of static aeroelastic deformation and Reynolds number effects; this 


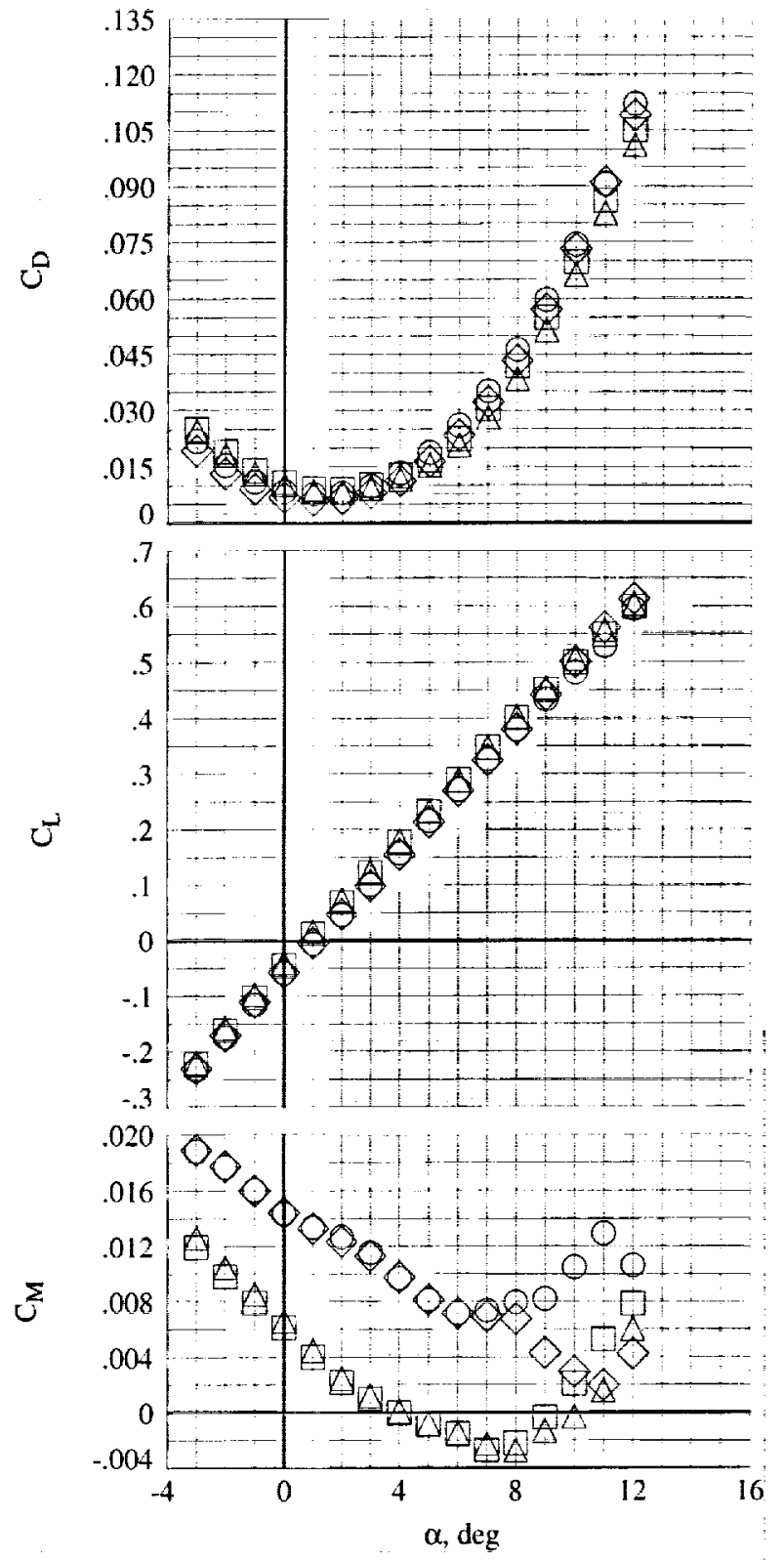

$\begin{array}{llll} & \text { Rn (millions) } & \text { q.psf } & \text { config } \\ \bigcirc & 10.23 & 967 . & \text { Baseline } \\ \square & 10.21 & 963 . & \text { Transonic cruise + nac } \\ \diamond & 79.61 & 1797 . & \text { Baseline } \\ \triangle & 79.59 & 1802 . & \text { Transonic cruise + nac }\end{array}$

Figure 7. Representative longitudinal force and moment data, $M=0.90$. fact is highlighted in figure 7 by the distinctly different dynamic pressure levels for the two Reynolds numbers. The discussion will address static aeroelastic effects as a means to isolate and more properly address Reynolds number effects.

\section{Repeatability}

Data presented herein was acquired over a series of wind-tunnel tests of the model. This section provides examples of both short-and longterm repeatability, as defined in reference 18. Additionally, the methodology outlined in reference 18 is used to quantify the short-term (within test / Mach series) repeatability in terms of a $95 \%$ confidence interval; a limited set of long term (test to test) repeated data dictated a simplified comparison of estimated mean data from test to test. The $95 \%$ confidence interval is interpreted as the bounds about an estimated mean (average of multiple, repeat polars) that encompasses the true mean value with a chance of $95 \%$.

Examples of short-term repeatability of longitudinal aerodynamic data are shown in figure 8 for the baseline and transonic cruise configurations at a Reynolds number of 80 million. The figure shows the residuals of the longitudinal coefficients defined as the difference in the individual measured data points from the estimated mean of the group of repeated polars; the estimated mean was the average of the grouped data based on piecewise, $2^{\text {nd }}$ order polynomial fits of the individual polars. The figure also indicates, with a solid line, the bounds of the $95 \%$ confidence interval as a function of angle of attack; the average confidence interval over the range of angle of attack is noted.

Results shown in figure 8 are typical of other test conditions. In general, the coefficient residuals are small up to angles-of-attack of approximately 6 to $8 \mathrm{deg}$. Beyond this angle of attack range, larger-scale separations begin to dominate the wing flow field as indicated by the more nonlinear behavior exhibited in the pitching moment coefficient data and the increasing variations in all of the residual data. For reference, the average $95 \%$ confidence interval values for each coefficient at each test condition are included in table 4. These values were used to determine the significance of the differences observed in the data. Figure 9 provides an indication of typical long term repeatability. In general, the test to test repeatability is similar to the within test repeatability. 

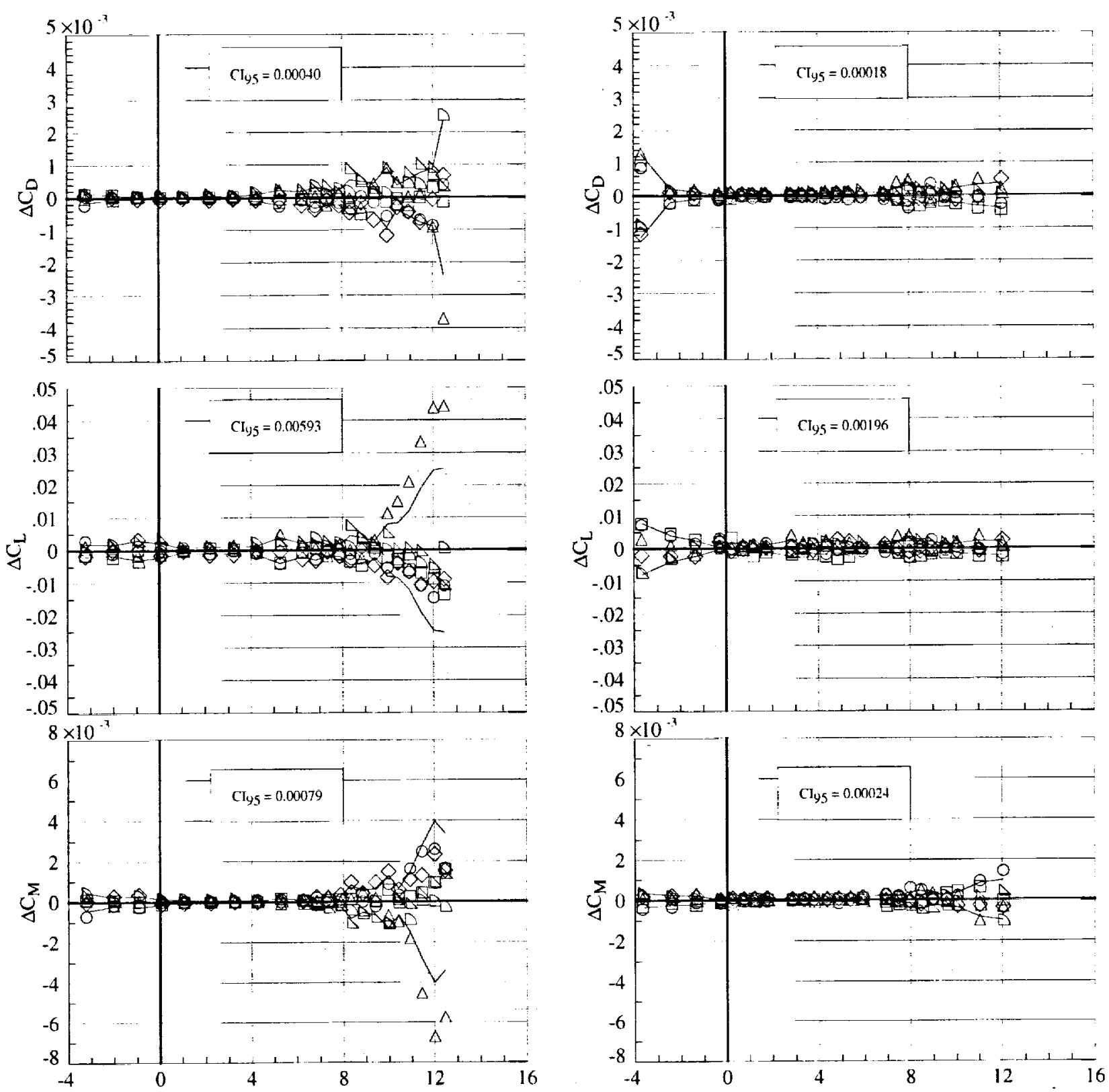

$\alpha$, deg

$\alpha, \operatorname{deg}$

$\begin{array}{lllll} & \text { Rn (millions) } & \mathbf{P}_{\mathrm{T}}, \mathrm{psi} & \mathrm{T}_{\mathrm{T}},{ }^{\circ} \mathrm{F} & \mathbf{q}, \mathrm{psf} \\ \mathrm{O} & 80.11 & 37.33 & -250.1 & 1798 . \\ \square & 79.44 & 37.31 & -249.1 & 1796 . \\ \diamond & 79.93 & 37.27 & -250.1 & 1794 . \\ \Delta & 79.50 & 37.32 & -249.1 & 1798 . \\ \Delta & 79.34 & 37.27 & -248.9 & 1798 . \\ \Delta & 79.35 & 37.27 & -248.9 & 1798 .\end{array}$

a) Baseline configuration.

Figure 8. Short-term repeatability, $M=0.90$.

$\begin{array}{lllll} & \text { Rn (millions) } & \mathbf{P}_{\mathrm{T}}, \mathrm{psi} & \mathrm{T}_{\mathrm{T}},{ }^{\circ} \mathrm{F} & \mathrm{q}, \text { psf } \\ & & & & \\ \mathrm{O} & 79.50 & 37.29 & -249.1 & 1799 . \\ \square & 79.62 & 37.26 & -249.4 & 1798 . \\ \diamond & 79.96 & 37.43 & -249.4 & 1807 . \\ \Delta & 79.65 & 37.32 & -249.3 & 1801 . \\ \Delta & 79.34 & 37.31 & -248.7 & 1801 . \\ D & 79.45 & 37.32 & -248.9 & 1802 .\end{array}$

b) Transonic cruise configuration with nacelles.

Figure 8. Concluded. 

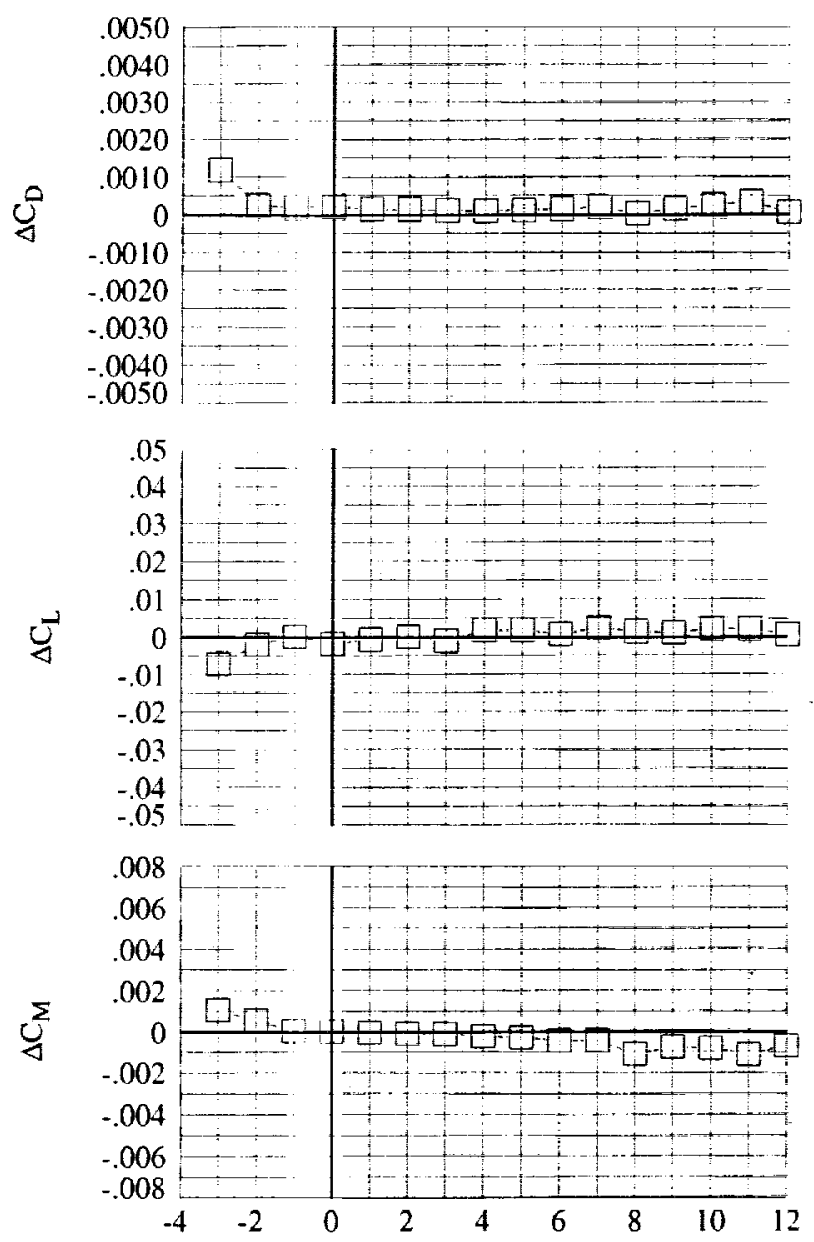

$\alpha, \operatorname{deg}$

Rn (millions) $\quad$ P. $_{\mathrm{T}}, \mathrm{psi} \quad \mathrm{T}_{\mathrm{T}},{ }^{\circ} \mathrm{F} \quad$ q. psf

$\begin{array}{llll}79.59 & 37.32 & -249.1 & 1802 .\end{array}$

Figure 9. Representative long-term (test to test) repeatability, baseline configuration, $M=0.90$.

The wing pressure data presented in this paper were not repeated. However, the consistency of the pressure coefficients at the lower angles of attack as well as the repeatability during the aeroelastic sweeps provided some confidence that pressure coefficient differences on the order of 0.1 are distinguishable.

\begin{tabular}{|c|c|c|c|c|}
\hline $\mathrm{Rn}, 10^{6}$ & q. psf & $\Delta \mathrm{C}_{\mathrm{D}}$ & $\Delta \mathrm{C}_{\mathrm{L}}$ & $\Delta \mathrm{C}_{\mathrm{M}}$ \\
\hline \hline 10.2 & 967 & 0.0001 & 0.0008 & 0.0001 \\
\hline 20.0 & 994 & 0.0001 & 0.0013 & 0.0002 \\
\hline 30.0 & 1003 & 0.0002 & 0.0018 & 0.0003 \\
\hline 30.0 & 1755 & 0.0002 & 0.0017 & 0.0003 \\
\hline 80.0 & 1797 & 0.0004 & 0.0059 & 0.0008 \\
\hline
\end{tabular}

a) Baseline configuration.

\begin{tabular}{|c|c|c|c|c|}
\hline $\mathrm{Rn}, 10^{6}$ & $\mathrm{q}, \mathrm{ps}$ & $\Delta \mathrm{C}_{\mathrm{D}}$ & $\Delta \mathrm{C}_{\mathrm{L}}$ & $\Delta \mathrm{C}_{\mathrm{M}}$ \\
\hline \hline 10.2 & 963 & 0.0002 & 0.0008 & 0.0002 \\
\hline 20.0 & 995 & 0.0001 & 0.0011 & 0.0002 \\
\hline 30.0 & 1005 & 0.0002 & 0.0012 & 0.0002 \\
\hline 30.0 & 1755 & 0.0002 & 0.0010 & 0.0002 \\
\hline 80.0 & 1801 & 0.0002 & 0.0020 & 0.0002 \\
\hline
\end{tabular}

b) Transonic cruise configuration with nacelles.

Table 4. Repeatability data, $M=0.90$ ( $95 \%$ confidence intervals averaged over $\alpha$ range).

\section{Static Aeroelastic Elfects}

Achieving high Reynolds numbers approaching those characteristic of flight requires the manipulation of both the total temperature and pressure, as seen in figure 6 . As a result, the static aeroelastic deformation of the model, in particular the wing, under load must be considered when attempting to isolate Reynolds number effects. Previous reports for high aspect ratio subsonic transport configurations have shown the static aeroelastic effects to be on the order of Reynolds number effects, and often opposite in sense to that of Reynolds number trends, thus masking the Reynolds number effects (ref. 19, 20). Like the subsonic transport configurations, the current low aspect ratio HSCT model is flexible under load, most notably on the thin outboard wing panel.

Video model deformation measurements of the wing under load were concentrated on the outboard wing panel. These measurements indicated that as the aerodynamic load on the wing increased, the outboard wing panel would tend to washout, similar to that observed on the higher aspect ratio subsonic transports. This type of wing bending occurs because the local lifting center of pressure is located behind the elastic axis of the wing, which produces a local nose-down torsional moment at each outboard wing section. Figure 10 shows representative wing twist data at $\eta=0.922$, relative to the wind-off twist, as a function of dynamic pressure and angle of attack. At the higher dynamic pressures and/or higher angles of 
AIAA-2001-0912
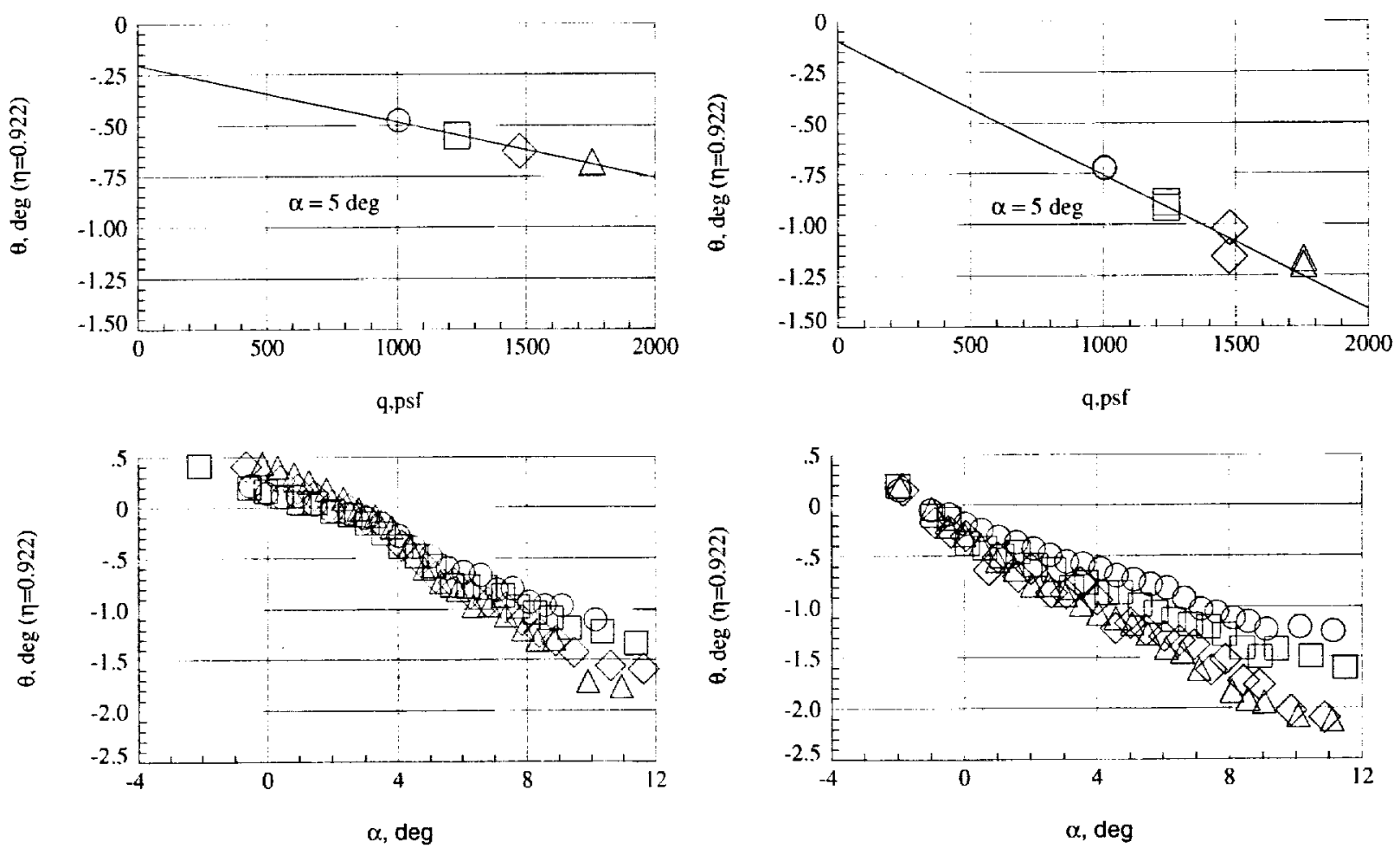

$\begin{array}{lll} & \text { Rn, (millions) } & \text { q.psf } \\ \square & 29.76 & 1004 \\ & 29.98 & 1231 \\ & 30.01 & 1475 \\ & 30.01 & 1755 .\end{array}$

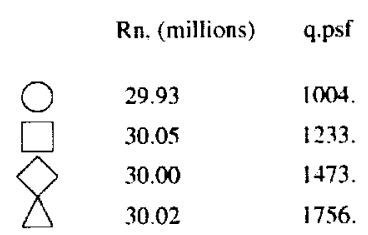

a) Baseline configuration with nacelles.

Figure 10. Outboard wing twist change under load, $M=0.90$.

attack, the local twist change increases (more nose-down) on the order of 2 deg. The relationship between local wing twist change and dynamic pressure is linear, at least over the range of dynamic pressure shown here. One would expect that extrapolation to the wind-off condition $(q=0 p s f)$ would indicate no twist change; the data at $\alpha=5$ deg does not produce this result, most likely due to measurement uncertainty.

The effects of static aeroelastic wing bending on the longitudinal aerodynamic data obtained are presented in figure 11. These data were obtained with a constant Reynolds number of 30 million for several total pressure (dynamic pressure) conditions, as shown in figure 6 . The force and moment results show trends consistent with the increasing washout of the wing with increasing load; for a constant body angle of attack, the lift decreases and the nose-up pitching moment increases with increasing dynamic pressure. The change in pitching moment is 

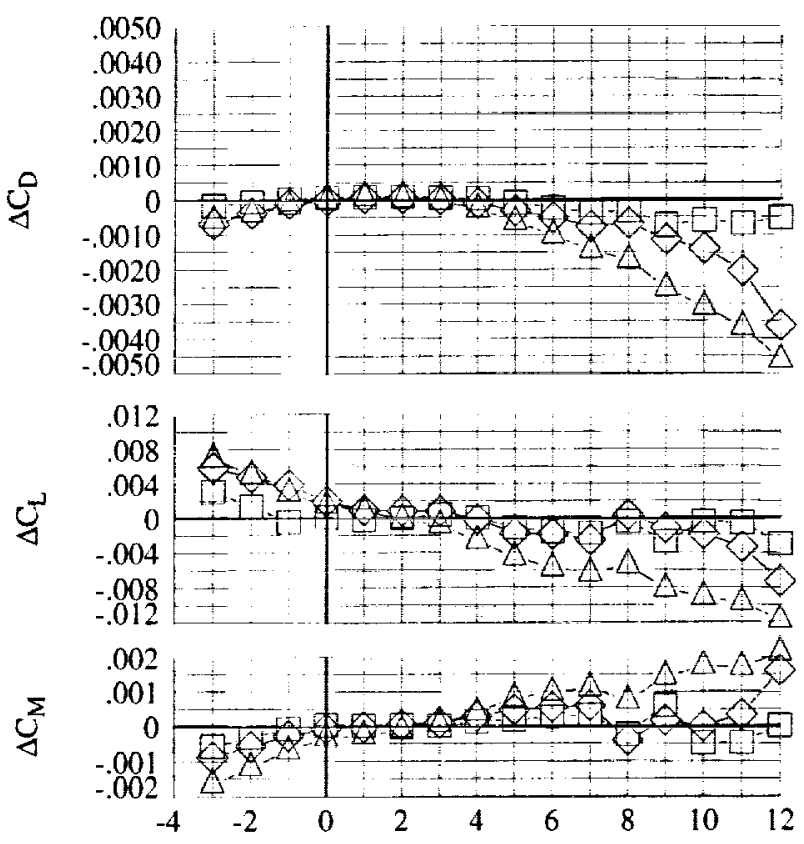

$\alpha, \operatorname{deg}$

$\begin{array}{lllll} & \text { Rn (millions) } & \mathrm{P}_{\mathrm{T}, \mathrm{psi}} & \mathrm{T}_{\mathrm{T},}{ }^{\circ} \mathrm{F} & \text { q. psf } \\ \square & 30.04 & 25.52 & -143.3 & 1232 . \\ & 30.07 & 30.51 & -100.8 & 1474 . \\ 30.04 & 36.36 & -52.19 & 1756 .\end{array}$

a) Baseline configuration with nacelles.

Figure 11. Static aeroelastic effects on longitudinal coefficlents, referenced to $q=1004 \mathrm{psf}, M=0.90$.

numbers. Studies on subsonic transports, and analysis of static aeroelastic sensitivity at other Reynolds numbers for this model (not shown) support the validity of these assumptions. As applied in this paper, force and moment coefficient data were adjusted to a nominal dynamic pressure of 1000 psf. Ideally, an adjustment would be made to shift the coefficient data to the wind-off condition $(q=0 p s f)$ to obtain results for the rigid, non-deformed model shape most frequently used in computational simulations. However, the large extrapolation to reach the wind-off condition introduces additional uncertainty and was not applied herein.

Adjustments for static aeroelastic effects were not applied to any of the wing pressure data presented in this paper. The effect on the wing pressure data was not significant because most of the pressure ports were inboard of the wing leading-edge break $(\eta=0.522)$, where model deformation was minimal.
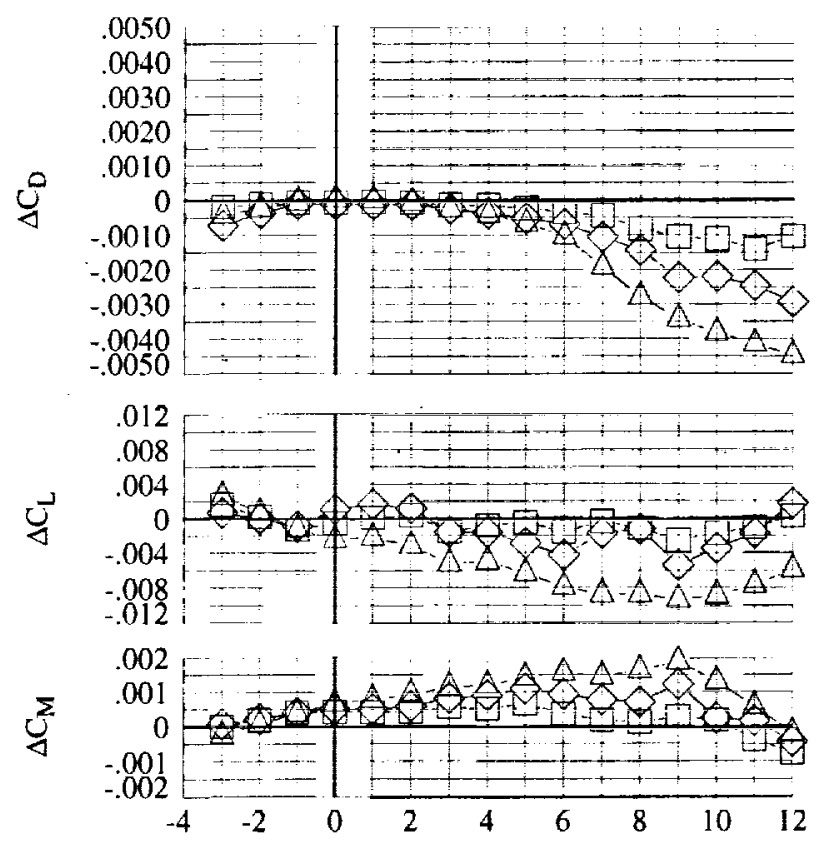

$\alpha, \operatorname{deg}$

\begin{tabular}{lllll} 
& Rn (millions) & $\mathrm{P}_{\mathrm{T}}, \mathrm{psi}$ & $\mathrm{T}_{\mathrm{T}},{ }^{\circ} \mathrm{F}$ & q. psf \\
$\square$ & 30.04 & 25.52 & -143.2 & 1233. \\
\hline 30.02 & 30.52 & -100.4 & 1474. \\
30.01 & 36.37 & -51.85 & 1756.
\end{tabular}

b) Transonic cruise configuration with nacelles.

Figure 11. Concluded.

\section{Reynolds Number Effects}

The main Reynolds number effects observed in the data were a drag reduction, a delay of leading-edge flow separation, and an increase in longitudinal stability with increasing Reynolds number. The following discussion will examine Reynolds number trends for the longitudinal force and moment coefficients (adjusted for static aeroelastic effects) at three angles of attack characterized as follows: 1) near minimum drag ( $\alpha$ $1 \mathrm{deg}$ ), 2) near transonic cruise ( $\alpha=5 \mathrm{deg}$ ), and 3) high angle of attack with significant wing leadingedge separation ( $\alpha=9 \mathrm{deg})$. Force and moment data for the baseline configuration and transonic cruise with nacelles configuration are presented for each angle of attack.

The Reynolds number effects for conditions near minimum drag are presented in figure 12. Drag decreased as the Reynolds number increased, and is mostly accounted for by the established trend of skin friction with Reynolds number. Theoretical skin friction drag for the 
configuration was calculated with equivalent flat plate theory, plus form factors, using the Blasius and Karman-Schoenherr incompressible skin friction correlations for laminar and turbulent boundary layers, respectively, with compressibility effects accounted for with the reference temperature method (ref. 21). As applied herein, the flat-plate theory assumed that the same extent of laminar flow was present on both the upper and lower outboard wing surfaces and that fully turbulent flow existed on both upper and lower surfaces of the inboard wing. In figure 12, the open symbols are experimental data acquired allowing free transition on the wing; filled symbols are experimental data acquired with the wing boundary layer transition fixed near the leading edge. Several theoretical curves are included where the variable is the extent of laminar flow on the outboard wing. All theoretical data was adjusted by a constant increment such that the fully turbulent theoretical curve was anchored to the experimental data for the 80 million Reynolds condition. Increments between the theoretical curves indicate the sensitivity of drag to the transition location on the outboard wing.

The fully turbulent theoretical skin friction drag trend aligned well with the experimental drag data obtained with the wing boundary layer tripped at low Reynolds numbers for the baseline configuration. The drag behavior at this angle of attack suggests that the change in drag observed is primarily due to skin friction changes. The increment between tripped and transition free data at the lower Reynolds number showed the effects of various extents of laminar boundary layer runs on the outboard wing for the baseline configuration. The extent of laminar flow inferred from figure 12 compares favorably with temperature sensitive paint measurements of the transition location on the outboard wing. No experimental data was obtained with fixed wing transition for the transonic cruise configuration. The character of the drag for this configuration with changing Reynolds number suggested, similar to that for the baseline configuration, that skin friction drag reduction was the dominant flow phenomenon. Note that the fully turbulent theoretical drag also agrees with the 120 million Reynolds number data point. All of this implies that the traditional skin friction drag scaling techniques are appropriate to capture the drag trends for attached flow on this class of vehicle.
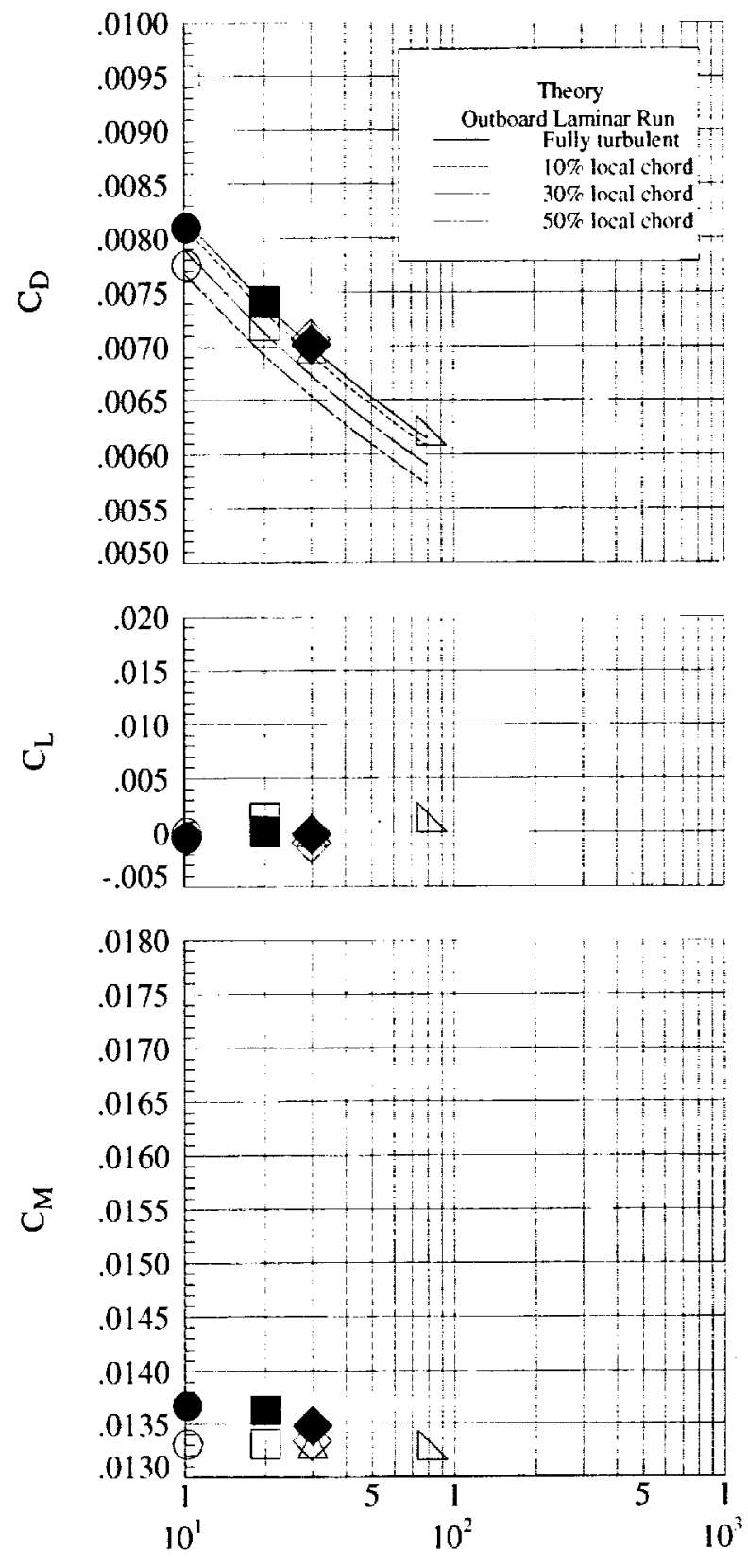

Rn (millions)

$\begin{array}{llllll} & \alpha, \text { deg } & \text { Rn (millions) } & \text { q. psf } & \mathbf{P}_{\mathrm{T}}, \mathrm{psi} & \mathrm{T}_{\mathrm{T}},{ }^{\circ} \mathrm{F} \\ \mathrm{O} & & & & & \\ \square & 1.1 & 10.23 & 967 . & 20.03 & 120.6 \\ \bigotimes & 1.1 & 20.03 & 994 . & 20.61 & -97.21 \\ \triangle & 1.1 & 29.83 & 1003 . & 20.78 & -184.0 \\ \triangle & 1.1 & 30.00 & 1755 . & 36.30 & -52.07 \\ & 1.1 & 79.61 & 1797 . & 37.29 & -249.4\end{array}$

a) Baseline configuration.

Figure 12. Longitudinal coefficient trends with Reynolds number, near minimum drag, $M=0.90$. (solid symbols = fixed transition on wing) (open symbols $=$ free transition on wing) 

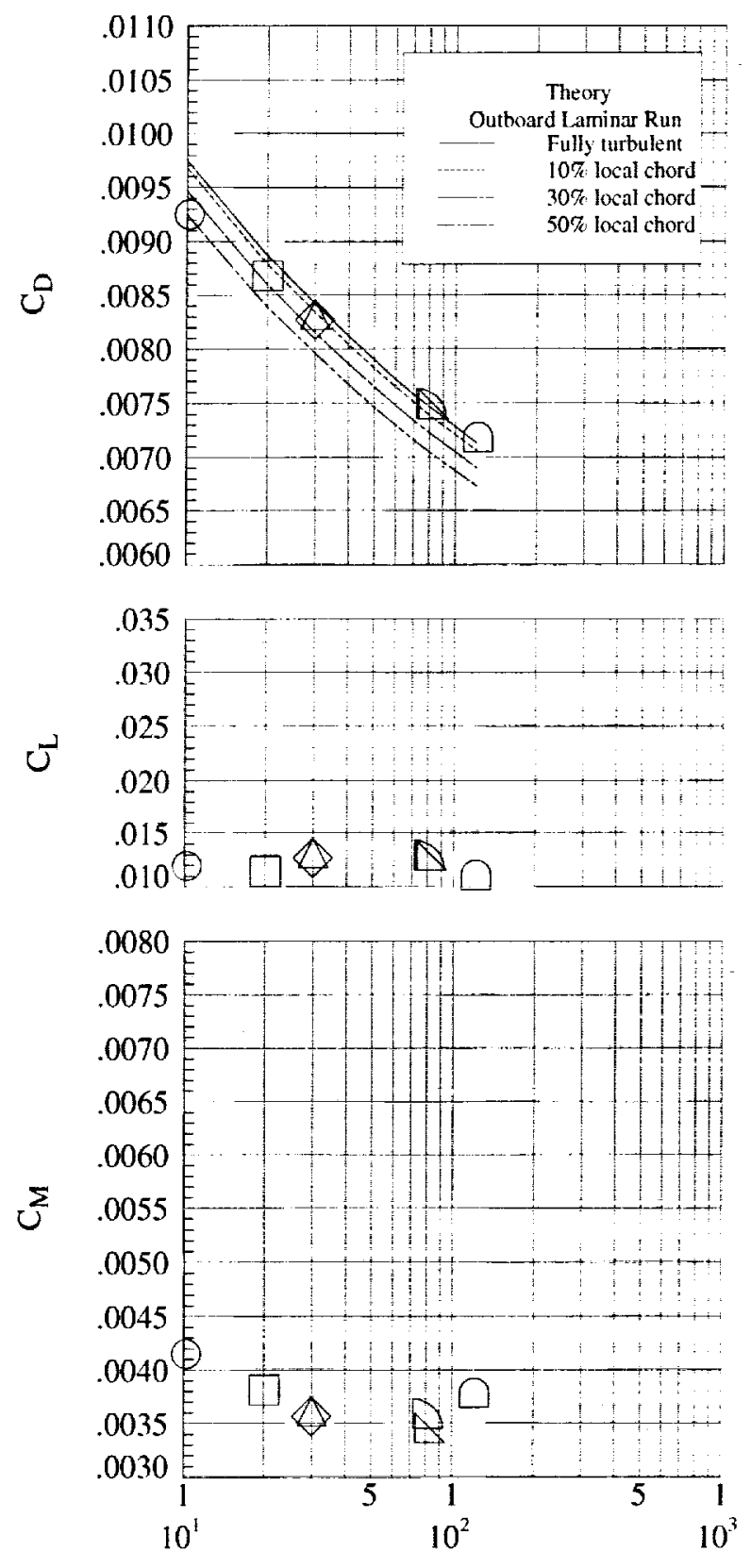

Rn (millions)

$\begin{array}{clllll} & \alpha, \text { deg } & \text { Rn (millions) } & \text { q, psf } & \mathrm{P}_{\mathrm{T}}, \mathrm{psi} & \mathrm{T}_{\mathrm{T}},{ }^{\circ} \mathrm{F} \\ \bigcirc & 1.0 & 10.21 & 963 . & 19.98 & 120.2 \\ \square & 1.0 & 20.05 & 995 . & 20.63 & -97.26 \\ \triangle & 1.0 & 29.92 & 1005 . & 20.82 & -184.2 \\ \square & 1.0 & 30.02 & 1755 . & 36.32 & -52.16 \\ \square & 1.0 & 79.59 & 1802 . & 37.32 & -249.1 \\ \square & 1.0 & 80.00 & 2677 . & 55.50 & -185.2 \\ \square & 1.0 & 120.78 & 2704 . & 56.11 & -250.5\end{array}$

b) Transonic cruise configuration with nacelles.

Figure 12. Concluded.
The lift trends with Reynolds number presented in figure 12 for both configurations show that the lift was essentially constant over the range of Reynolds numbers tested at this angle of attack. This implies that viscous effects do not substantially influence the lifting characteristics at this condition.

The pitching moment trends with Reynolds number presented in figure 12 show small to negligible changes at this angle of attack. For reference, the pitching-moment coefficients can be related to the effects of stabilizer deflection. The stabilizer effectiveness for the full configuration with empennage (when closed aftbody and horizontal tails are present) is approximately 0.005 change in pitching-moment coefficient for one degree of stabilizer deflection; one major division represents roughly $0.10 \mathrm{deg}$ of stabilizer to regain trim. For the baseline configuration, the transition free data was essentially constant, although the fixed wing transition data at the lower Reynolds numbers did show a small change. For the transonic cruise configuration, the Reynolds number effect is on the order a 0.1 deg stabilizer change.

The Reynolds number effect for conditions near the transonic cruise angle of attack are shown in figure 13. In general, the coefficient trends exhibit the same behavior as at the minimum drag condition. The change in drag coefficient was roughly the same as that seen at the minimum drag condition in figure 12 , suggesting that skin friction reduction remains the primary flow physics influence at this attitude. For the baseline configuration, the fixed transition data does not show a significant difference as compared to the free transition data, which suggests that the trip heights used to fix transition were no longer effective at this angle of attack. As with the minimum drag condition, the Reynolds number effects on lift were not significant near cruise conditions. Additionally, the lift-curve-slope at cruise conditions was not significantly affected by Reynolds number changes. The Reynolds number effect on the pitching moment was larger than that observed at the minimum drag conditions. The data show a nose-down change equivalent to a 0.2 to 0.3 deg stabilizer change with increasing Reynolds number. The increased nose-down character is related to the delay of the inboard wing leading-edge separation (vortex lift effects) with increasing Reynolds number; the delay of leading-edge separation will be discussed further below. Additionally, the longitudinal stability 
AIAA-2001-0912
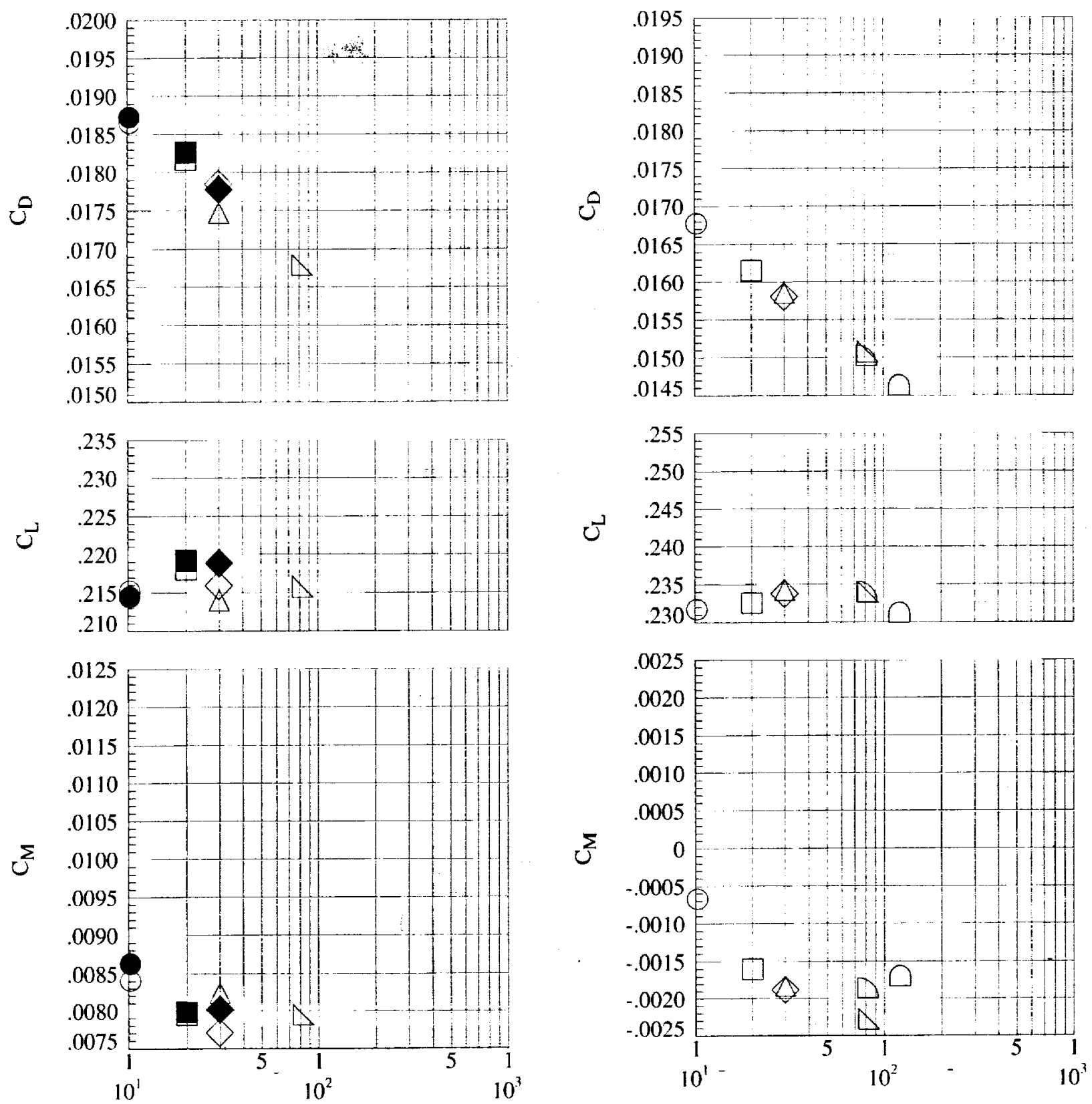

Rn (millions)

\begin{tabular}{|c|c|c|c|c|}
\hline$\alpha, \operatorname{deg}$ & Rn (millions) & $q, p s f$ & $\mathrm{P}_{\mathrm{T}} \cdot \mathrm{psi}$ & $\mathbf{T}_{\mathrm{T}} \cdot{ }^{\circ} \mathrm{F}$ \\
\hline 5.0 & 10.23 & 967. & 20.03 & 120.6 \\
\hline 5.0 & 20.03 & 994. & 20.61 & -97.21 \\
\hline 5.0 & 29.83 & 1003 & 20.78 & -184.0 \\
\hline 5.0 & 30.00 & 1755. & 36.30 & -52.07 \\
\hline 5.0 & 79.61 & 1797. & 37.29 & -249.4 \\
\hline
\end{tabular}

a) Baseline configuration.

Figure 13. Longitudinal coefficient trends with Reynolds number, near transonic cruise, $M=0.90$. (solid symbols = fixed transition on wing)

(open symbols = free transition on wing)

Rn (millions)

$\begin{array}{clllll} & \alpha, \text { deg } & \text { Rn (millions) } & \text { q. psf } & \mathrm{P}_{\mathbf{T}}, \mathrm{psi} & \mathbf{T}_{\mathbf{T}},{ }^{\circ} \mathrm{F} \\ \bigcirc & 5.0 & 10.21 & 963 . & 19.98 & 120.2 \\ \square & 5.0 & 20.05 & 995 . & 20.63 & -97.26 \\ \triangle & 5.0 & 29.92 & 1005 . & 20.82 & -184.2 \\ \triangle & 5.0 & 30.02 & 1755 . & 36.32 & -52.16 \\ \square & 5.0 & 79.59 & 1802 . & 37.32 & -249.1 \\ \square & 5.0 & 80.00 & 2677 . & 55.50 & -185.2 \\ \square & 5.0 & 120.78 & 2704 . & 56.11 & -250.5\end{array}$

b) Transonic cruise configuration with nacelles.

Figure 13. Concluded. 
AIAA-2001-0912
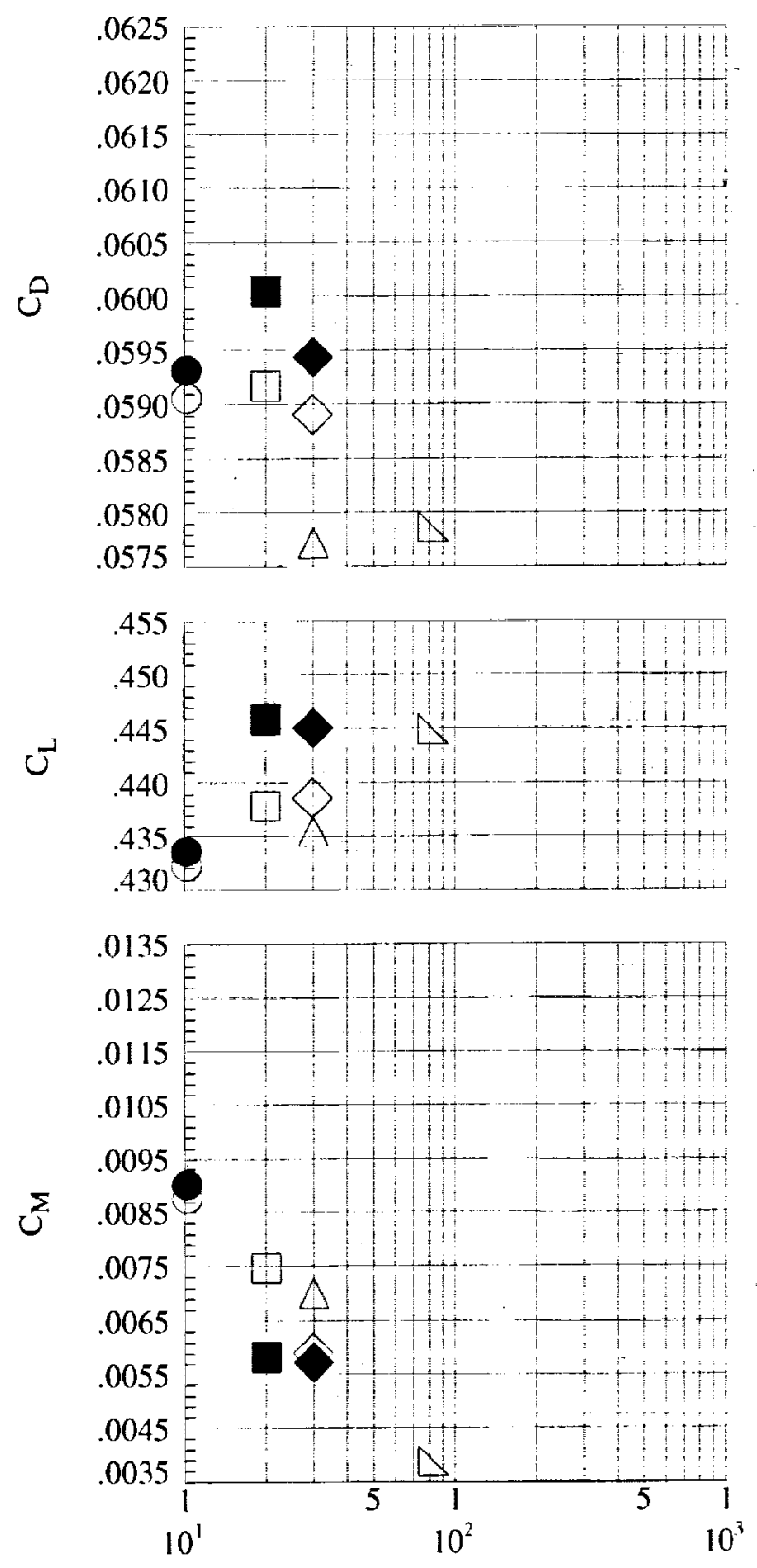

Rn (millions)

$\begin{array}{cccccc} & \alpha, \text { deg } & \text { Rn (millions) } & \text { q. psf } & \mathrm{P}_{\mathrm{T} .} \text { psi } & \mathrm{T}_{\mathrm{T},}{ }^{\circ} \mathrm{F} \\ \bigcirc & 9.0 & 10.23 & 967 . & 20.03 & 120.6 \\ \square & 9.0 & 20.03 & 994 . & 20.61 & -97.21 \\ \triangle & 9.0 & 29.83 & 1003 . & 20.78 & -184.0 \\ \triangle & 9.0 & 30.00 & 1755 . & 36.30 & -52.07 \\ \square & 9.0 & 79.61 & 1797 . & 37.29 & -249.4\end{array}$

a) Baseline configuration.

Figure 14. Longitudinal coefficient trends with Reynolds number, high angle of attack, $M=0.90$.

(solid symbols = fixed transition on wing)

(open symbols = free transition on wing)
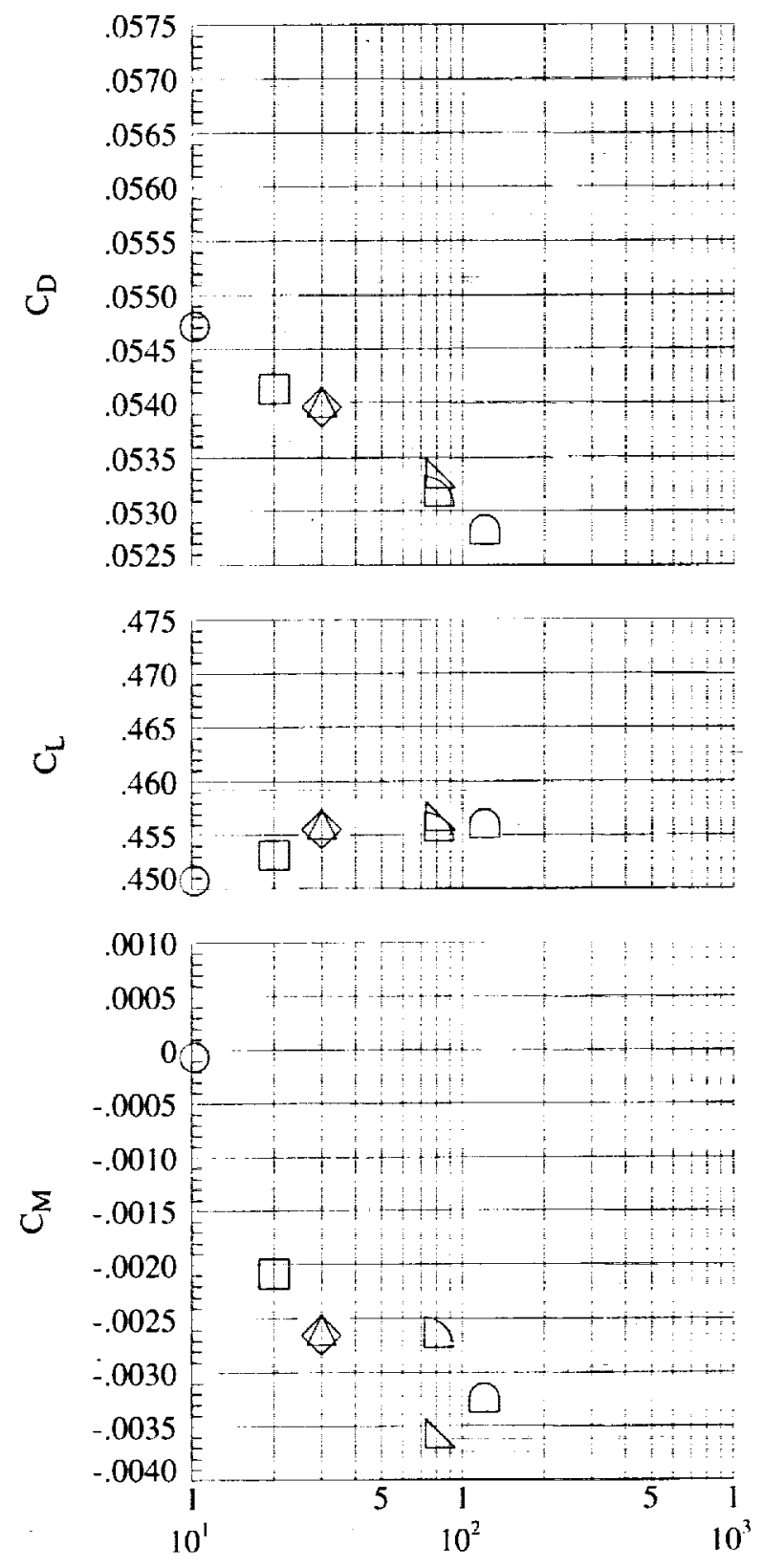

Rn (millions)

$\alpha$, deg Rn (millions) $\quad$ q, psf $\quad \mathrm{P}_{\mathrm{T}}, \mathrm{psi} . \quad \mathrm{T}_{\mathrm{T}},{ }^{\circ} \mathrm{F}$

$\begin{array}{llllll}\bigcirc & 9.0 & 10.21 & 963 . & 19.98 & 120.2 \\ \square & 9.0 & 20.05 & 995 . & 20.63 & -97.26 \\ \triangle & 9.0 & 29.92 & 1005 . & 20.82 & -184.2 \\ \triangle & 9.0 & 30.02 & 1755 . & 36.32 & -52.16 \\ \square & 9.0 & 79.59 & 1802 . & 37.32 & -249.1 \\ \square & 9.0 & 80.00 & 2677 . & 55.50 & -185.2 \\ \square & 9.0 & 120.78 & 2704 . & 56.11 & -250.5\end{array}$

b) Transonic cruise configuration with nacelles.

Figure 14. Concluded.

14

American Institute of $\mathrm{Ae}^{\prime}$ autics and Astronautics 
AIAA-2001-0912

increased as the neutral point moved aft by $0.73 \%$ and $0.13 \%$ of the mean aerodynamic chord at $\alpha=$ $5 \mathrm{deg}$ for the baseline and transonic cruise configurations, respectively.

The Reynolds number effect for a high angle of attack condition beyond pitch up is shown in figure 14. At this attitude, the flowfield is dominated by separated flow which can cause increased data variability; this was particularly evident for the baseline configuration. The change in drag coefficient for the transonic cruise configuration is similar to that at the lower angles of attack. Unlike the lower angles of attack, the lift coefficient data show a clear, though small, increase with increasing Reynolds number. As at the lower angles of attack, the pitching moment data show a increased nose-down moment with increasing Reynolds number. The magnitude of the change, however, is much more pronounced ( 0.8 degree stabilizer change) at this high attitude. Both the slight lift increase and the more significant nose down character with increasing Reynolds number implies that the outboard wing panel performance was still improving.

As mentioned previously, increased nosedown pitch characteristics at transonic cruise and high angle of attack conditions are related to the delay of the inboard wing leading-edge separation with increasing Reynolds number. Figure 15 shows the local flow behavior at or near the wing leading edge as a function of angle of attack. The pressure coefficient at $\eta=0.405$ is representative of the local flow behavior observed on the blunt inboard wing leading edge. The pressure coefficient at $\eta=0.619$ is representative of the local flow behavior observed near $(\sim 10 \%$ of local chord from the leading edge) the sharper outboard wing leading edge. For both configurations, the pressures were more sensitive to Reynolds number changes at the higher angles of attack inboard than outboard, as expected due to the leading edge shape. For both configurations, the flow separation on the inboard leading edge was delayed to higher angles of attack as the Reynolds number increased; recall that both the baseline and transonic cruise configurations have identical, undeflected inboard leading edges. On the outboard wing, the pressure for the baseline configuration was nearly flat beyond an angle of attack of approximately 8 deg indicating substantial flow field separation. The deflected, outboard wing leading edge of the transonic cruise configuration delays the onset of separation to a higher angle of attack.
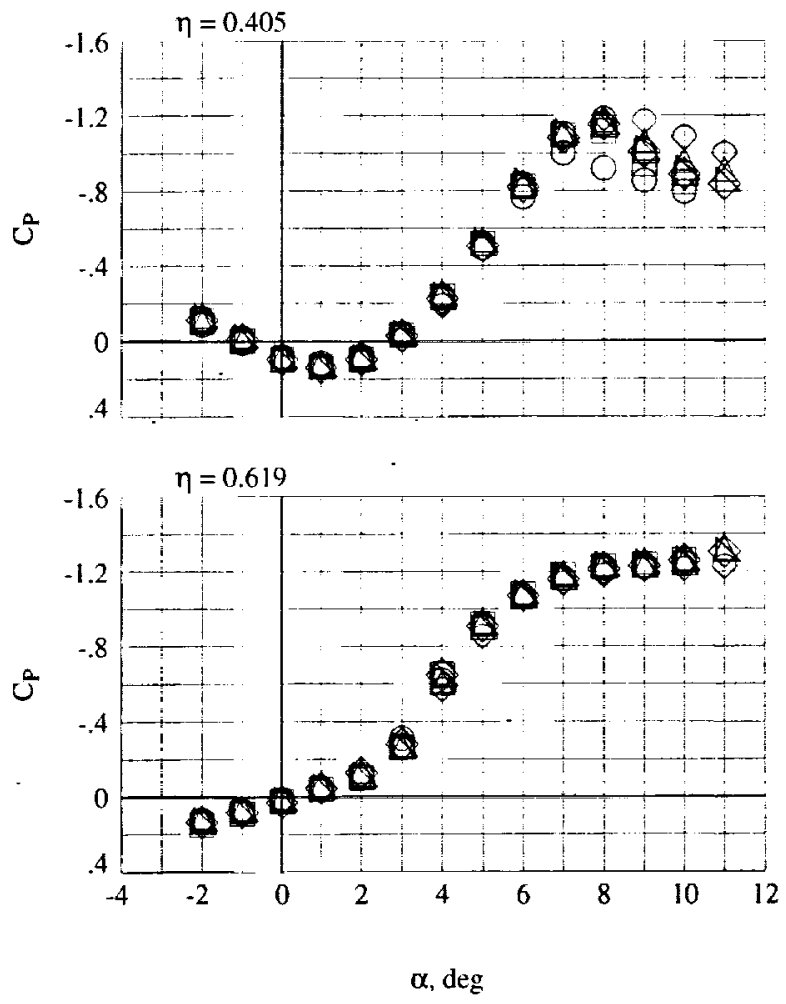

$\begin{array}{llll} & \text { Rn (millions) } & \text { q. psf } & \mathrm{T}_{\mathrm{T} .}{ }^{\circ} \mathrm{F} \\ \mathrm{O} & 10.24 & 967 . & 120.1 \\ \square & 20.10 & 996 . & -97.78 \\ \triangle & 29.77 & 1004 . & -183.2 \\ \triangle & 29.98 & 1231 . & -142.9 \\ \triangle & 30.01 & 1475 . & -100.2 \\ \square & 30.02 & 1755 . & -52.29 \\ \square & 30.02 & 1755 . & -52.29 \\ \bigcirc & 79.66 & 1798 . & -249.4\end{array}$

a) Baseline configuration with nacelles.

Figure 15. Wing leading-edge pressure characteristics, $M=0.90$.

To further illustrate the delay of leading edge separation, figures 16 and 17 show pitching moment increments highlighting the effect of Reynolds number. In figure 16 , the increments are referenced to the lowest Reynolds number condition, 10.2 million, at the low dynamic pressure level. Increasing the Reynolds number from 10 to 30 million produces a more nose down pitching moment, especially at the higher angles of attack for the baseline configuration. Since the stabilizer effectiveness is 0.005 per degree, stabilizer changes of approximately 1 and 0.5 deg for baseline and transonic cruise configurations, respectively, are required to trim out the Reynolds number effect from 10 to 30 million. In figure 17 , the increments are referenced to the lowest 

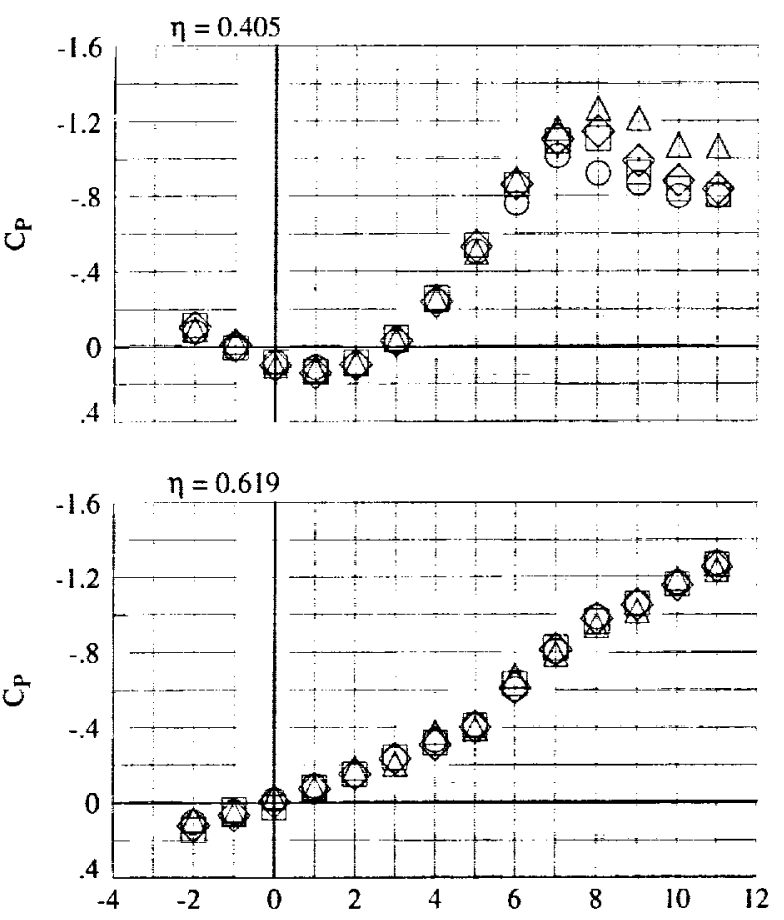

$\alpha, \operatorname{deg}$

$\begin{array}{llll} & \text { Rn (millions) } & \text { q. psf } & \mathrm{T}_{\mathrm{T}},{ }^{\circ} \mathrm{F} \\ \bigcirc & 10.24 & 967 . & 120.4 \\ \square & 20.04 & 996 . & -96.87 \\ \bigotimes & 29.96 & 1007 . & -184.2 \\ \triangle & 79.74 & 1797 . & -249.5\end{array}$

b) Transonic cruise configuration.

Figure 15. Concluded.

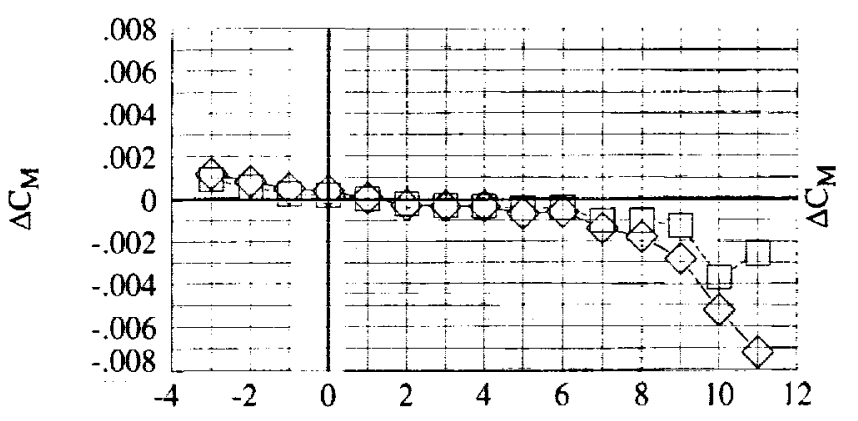

$\alpha$, deg

$\begin{array}{lllll} & \text { Rn (millions) } & \mathrm{P}_{\mathrm{T}}, \mathrm{psi} & \mathrm{T}_{\mathrm{T}} \cdot{ }^{\circ} \mathrm{F} & \text { q. psf } \\ \square & 20.03 & 20.61 & -97.21 & 994 . \\ & 29.83 & 20.78 & -184.0 & 1003 .\end{array}$

a) Baseline configuration.
Reynolds number condition, 30 million, at the higher dynamic pressure level. Similar to the lower dynamic pressure Reynolds number sweep, stabilizer changes of approximately 1 and $0.5 \mathrm{deg}$ for baseline and transonic cruise configurations, respectively, are required to trim out the Reynolds number effect from 30 to 80 million. Note that these stabilizer changes are additive to cover Reynolds numbers from 10 to 80 million, resulting in stabilizer changes of approximately 2 and $1 \mathrm{deg}$ for the baseline and transonic cruise configurations, respectively.

Figure 16. Pitch-up delay with Reynolds number at low dynamic pressure, $\mathbf{M}=0.90$. 


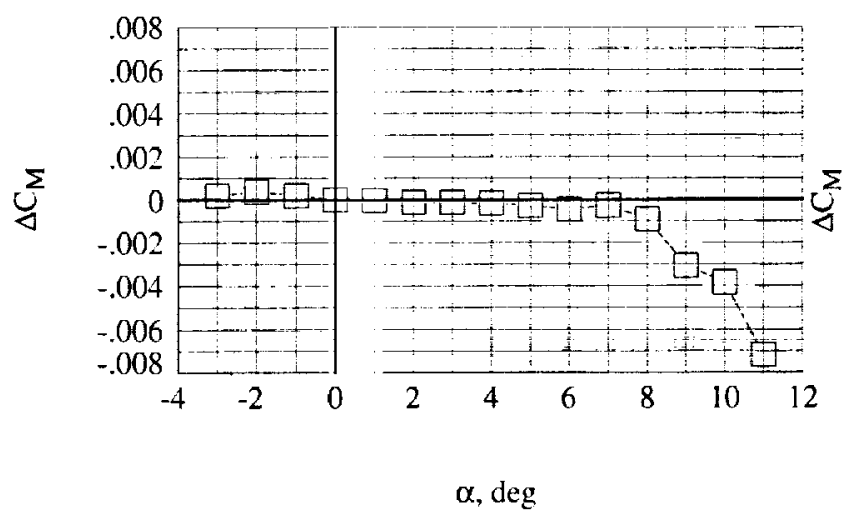

Rn (millions) $\quad \mathrm{P}_{\mathrm{T}}, \mathrm{psi} \quad \mathrm{T}_{\mathrm{T}},{ }^{\circ} \mathrm{F} \quad \mathrm{q}, \mathrm{psf}$

79.61

37.29

$-249.4 \quad 1797$.

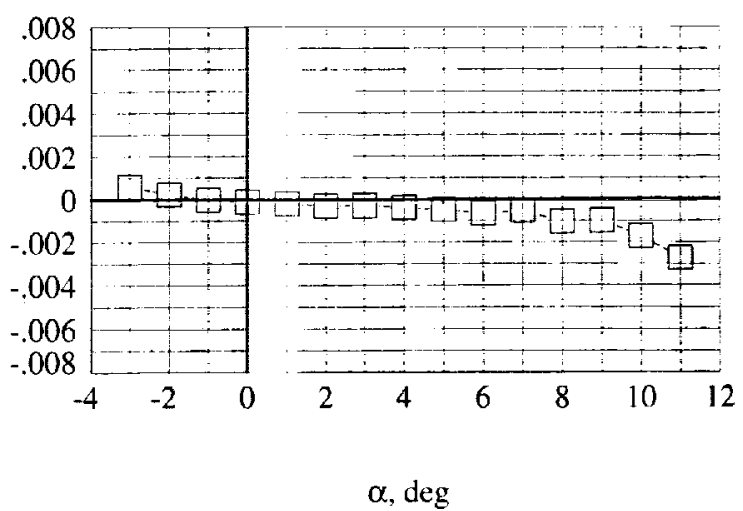

Rn (millions) $\quad \mathrm{P}_{\mathrm{T}}, \mathrm{psi} \quad \mathrm{T}_{\mathrm{T}},{ }^{\circ} \mathrm{F} \quad \mathrm{q}, \mathrm{psf}$

79.59

37.32

$-249.1 \quad 1802$.

b) Transonic cruise configuration with nacelles.

Figure 17. Pitch-up delay with Reynolds number at high dynamic pressure, $\mathbf{M}=\mathbf{0 . 9 0}$.

\section{CONCLUDING REMARKS}

A series of wind tunnel tests with a $2.2 \%$ scale HSCT model was executed in the NTF at NASA LaRC across a wide range of Reynolds numbers from that available in conventional wind tunnels to near flight condition at subsonic and transonic Mach numbers. Results were presented which focus on both the Reynolds number and static aeroelastic sensitivities of longitudinal characteristics at Mach 0.90 for the configuration without the empennage. General conclusions are summarized as follows:

1. Static aeroelastic effects were significant. Increasing the dynamic pressure at constant Mach and Reynolds numbers increases the washout of the outboard wing, which in turn contributes to a decrease of the lift-curve slope and decreased pitch stability.

2. Adjustments for static aeroelastic effects can be determined and applied to enable investigation of pure Reynolds number effects. Static aeroelastic effects mask Reynolds number effects if not isolated. This was particularly evident in the pitching moment data for this configuration.

3. Reynolds number effects are generally small for attached flow conditions; lift is insensitive and pitch stability increases on the order of $0.6 \%$ mean aerodynamic chord. Drag is dominated by scaleable skin friction correlations, assuming transition locations are known.
4. Reynolds number effects are larger when separated flow dominates at angles of attack above transonic cruise conditions. Separation on the blunt inboard leading edge in particular is sensitive, and significantly impacts the pitching moment characteristics. Stabilizer deflections of up to approximately $2 \mathrm{deg}$ are required to trim out the effect of Reynolds number from 10 to 80 million, depending on the wing configuration.

\section{ACKNOWLEDGEMENTS}

The authors would like to thank our many partners from industry and the staff of the NTF for making these tests successful. In particular, we would like to acknowledge Chet Nelson (Boeing), Marvine Hamner (Boeing/McDonnell Douglas), and Susan Williams (NASA-retired) who invested considerable effort over many years towards the development and testing of this model.

\section{REFERENCES}

1. McKinney, L.W. and Baals, D.D. (editors): "Wind-Tunnel/Flight Correlation - 1981," NASA CP 2225, November 1981.

2. "Boundary-Layer Simulation and Control in Wind Tunnels," AGARD AR-224, Report of the Fluid Dynamics Panel Working Group 09, 1988.

3. Goldhammer, M.E. and Steinle, F.W. Jr.: "Design and Validation of Advanced Transonic Wings Using CFD and Very High Reynolds 
Number Wind Tunnel Testing," $17^{\text {th }}$ ICAS Congress, September 1990.

4. Lynch, F.T.: "Experimental Necessities for Subsonic Transport Configuration Development," AIAA Paper 92-0158, January 1992.

5. Bushnell, D.M., Yip, L.P., Yao, C.S., Lin, J.C., Lawing, P.L., Batina, J.T., Hardin, J.C., Horvath, T.J., Fenbert, J.W., and Domack, C.S.: "Reynolds Number Influences in Aeronautics," NASA TM 107730, May 1993.

6. Wilhite, A. W., and Shaw, R. J.: "An Overview of NASA's High-Speed Research Program," $20^{\text {th }}$ ICAS Congress, Paper 112, August 2000.

7. Nelson, C.P.: "Effects of Wing Planform on HSCT Off-Design Aerodynamics," AIAA Paper 92-2629, June 1992.

8. Owens, L.R., and Wahls, R.A.: "Reynolds Number Effects on a Supersonic Transport at Subsonic, High-Lift Conditions," AIAA Paper 2001-0911, January 2001.

9. Gloss, B. B.: "Current Status and Some Future Test Directions for the US National Transonic Facility," Wind Tunnels and Wind Tunnel Test Techniques, R. Aeronaut. Soc., 1992, pp. 3.1-3.7.

10. Igoe, W.B.: "Analysis of Fluctuating Static Pressure Measurements in the National Transonic Facility," NASA TP-3475, March 1996.

11. Bobbitt, C.W., Hemsch, M.J., and Everhart, J.L.: "NTF Characterization Status," AIAA Paper 2001-755, January 2001.

12. Fuller, D.E.: "Guide for Users of the National Transonic Facility," NASA TM-83124, 1981.

13. Finley, T.D. and Tcheng, P.: "Model Attitude Measurements at NASA Langley Research Center," AIAA Paper 92-0763, 1992.

14. Burner, A.W., Erickson, G.E., Goodman, W.L., and Fleming, G.A.: "HSR Model Deformation Measurements from Subsonic to Supersonic Speeds," 1998 NASA High-Speed Research Program Aerodynamic Performance Workshop, February 1998, NASA/CP-1999209692, Vol. 1, p. 1569-1588.

15. Foster, J.M. and Adcock, J.B.: "User's Guide for the National Transonic Facility Research Data System," NASA TM-110242, April 1996.

16. Williams, M.S.: "Experience with Strain Gage Balances for Cryogenic Wind Tunnels," AGARD-R-774, 1989, pp. 18.1-18.14.

17. Braslow, A.L., and Knox, E.C.: "Simplified Method for Determination of Critical Height of Distributed Roughness Particles for Boundary-
Layer Transition at Mach Numbers from 0 to 5," NACA TN-4363, 1958.

18. Wahls, R.A., Adcock, J.B., Witkowski, D.P., and Wright, F.L.: "A Longitudinal Aerodynamic Data Repeatability Study for a Commercial Transport Model in the National Transonic Facility," NASA TP-3522, August 1995.

19. Wahls, R.A., Gloss, B.B., Flechner, S.G., Johnson, W.G.,Jr., Wright, F.L., Nelson, C.P., Nelson, R.S., Elzey, M.B., and Hergert, D.W.: "A High Reynolds Number Investigation of a Commercial Transport Model in the National Transonic Facility," NASA TM-4418, April 1993.

20. Al-Saadi, J.A.: "Effect of Reynolds Number, Boundary-Layer Transition, and Aeroelasticity on Longitudinal Aerodynamic Characteristics of a Subsonic Transport Wing," NASA TP3655, September 1997.

21. Sommer, S.C., and Short, B.J.: "Free-Flight Measurements of Turbulent-Boundary-Layer Skin Friction in the Presence of Severe Aerodynamic Heating at Mach Numbers from 2.8 to 7.0," NASA TN-3391, March 1955. 